\title{
Alternative RNA Splicing in the Pathogenesis of GBM
}

\author{
Amy Haseley Thorne ${ }^{1}$, Webster K. Cavenee ${ }^{1,2}$, Frank B. Furnari ${ }^{1,2,3 *}$ \\ ${ }^{1}$ Ludwig Institute for Cancer Research, ${ }^{2}$ The Moores Cancer Center, ${ }^{3}$ The Department of Pathology, University of California San \\ Diego, La Jolla, CA, 92093, US
}

ahthorne@ucsd.edu, wcavenee@ucsd.edu, ffurnari@ucsd.edu

*To whom correspondence should be addressed:

Frank Furnari, Ph.D.

Ludwig Institute for Cancer Research

University of California-San Diego School of Medicine

9500 Gilman Drive, CMM-East, Rm 3055

La Jolla, CA, 92093-0660

Phone: 858-534-7819

Fax: 858-534-7750

ffurnari@ucsd.edu

\begin{abstract}
Alternative splicing enables the generation of different proteins from a single gene, greatly increasing the use of genetic information. The resultant protein isoforms often have different biological properties effecting the phenotype of the cell in which it is expressed. Dysregulation of alternative splicing is a common occurrence in cancer and may lead to the formation of truncated or degraded proteins through the introduction of immature stop codons or nonsense mediated decay. Increasing evidence indicates that cancerassociated splicing variants play an important role in tumor initiation and progression. In this review, we summarize the evidence supporting the relevance of alternative splicing in glioblastoma multiforme (GBM). Specifically, we focus on the role of alternative splicing in GBM pathogenesis with an emphasis on the effect of aberrant alternative splicing of FGFR, GLI-1, and EGFR. The significance of exploiting alternatively spliced isoforms as potential biomarkers which may contribute to the development of diagnostic and prognostic methods, in addition to serving as molecular targets in GBM, will be discussed.
\end{abstract}

Keywords—glioblastoma; alternative splicing 


\section{INTRODUCTION}

Alternative splicing is a key regulator of gene expression and enables the generation of numerous transcripts from a single gene, thereby increasing the coding potential of the genome. During mRNA processing, approximately $90 \%$ of premRNA is removed as introns, with the remaining $10 \%$ joined together as exonic sequences (Tazi, Bakkour, and Stamm 2009). Thus the process has been considered a key driver in the evolution of phenotypic complexity. Splicing is the process by which introns are removed from a precursor mRNA (pre2mRNA) and exons are ligated to form a mature mRNA. Considered one of the most complicated RNA- protein complexes within the eukaryotic cell (Nilsen 2003), pre-mRNA splicing is catalyzed by the spliceosome, a large complex composed of five small nuclear ribonucleoprotein (RNP) subunits each composed of a single uridine rich small nuclear RNA (snRNA) in addition to as many as 150 proteins that assemble in an ordered stepwise manner on each intron to be spliced [reviewed in (Kim, Goren, and Ast 2008, Smith, Query, and Konarska 2008, Wahl, Will, and Luhrmann 2009)]. The spliceosome performs the two primary functions of splicing: recognition of the intron/exon boundaries and catalysis of the cut and paste reactions that remove introns and join exons. It is responsible for directing both constitutive and alternative splicing (Faustino and Cooper 2003).

Definition of the exon/intron boundary is maintained through cis-regulatory RNA elements which serve as splicing enhancers or silencers, essentially determining the splice site. Splicing regulatory elements (SREs) fall into four different categories: exonic splicing enhancers (ESEs), intronic splicing enhancers (ISEs), exonic splicing silencers (ESSs), and intronic splicing silencers (ISSs) (Matera and Wang 2014). These SREs function by recruiting trans-acting splicing factors which can either activate or suppress different steps of the splicing reaction (Matera and Wang 2014). Additionally, splicing factors help regulate splicing by interacting with the core components of the spliceosome. Some common splicing factors include serine-arginine rich (SR) proteins which recognize ESEs to promote splicing, and heterogenous nuclear ribonucleoproteins (hnRNPs) which recognize ESSs to inhibit splicing. The activity of splicing factors and SREs is contextdependent with the most frequent form of alternative splicing being expression of a cassette exon (exon skipping). Other alternative splicing modes include mutual exclusivity, use of alternative 3' or 5' splice sites, alternate transcriptional start sites, and intron retention [Figure 1, (Tazi, Bakkour, and Stamm 2009)].

Dysregulation of splicing has been associated with several human diseases including spinal muscular atrophy, Alzheimer's disease, and Parkinson's disease (Zhang et al. 2008, Glatz et al. 2006, Fu et al. 2013), and its connection with cancer, resulting in the activation of oncogenes or inactivation of tumor suppressors, has been well established [reviewed in (Oltean and Bates 2014, Zhang and Manley 2013, David and Manley 2010)]. For example, the splicing factor SF2/ASF, up-regulated in a variety of cancer types, acts as a proto-oncogene by affecting the alternative splicing of BIN1, S6K1 and MNK2. Specifically, expression of SF2/ASF inhibited the tumor suppressor function of BIN1 by inclusion of exon 12A, induced expression of the oncogenic isoform 2 of S6K1, and increased the phosphorylation of eIF4E by inducing expression of MNK2b. Targeted inhibition of SF2/ASF by shRNA abolished NIH-3T3 cellular transformation and significantly reduced tumorigenesis in vivo (Karni et al. 2007).

In this review, we will discuss alternative splicing in glioblastoma multiforme (GBM), the most common and lethal primary tumor of the central nervous system. GBM is classified by the World Health Organization as a grade IV astrocytoma, and is characterized by the presence of tumor cell necrosis and/or microvascular proliferation, in addition to cytological atypia, anaplasia, and mitotic activity (Louis et al. 2007). The current standard of care for GBM patients includes concomitant and adjuvant temozolomide plus radiotherapy, and leaves patients with a median survival of only about 15 months from the time of diagnosis (Stupp et al. 2005, Weller et al. 2014). The dismal prognosis for GBM patients provides a strong incentive for further research; a better understanding of the molecular alterations in GBM, such as aberrant alternative splicing, may help contribute to the discovery of future therapies.

Importantly, the recent characterization of the genome and transcriptome of GBM has enabled the use of comprehensive bioinformatics approaches in the investigation of alternative splicing in GBM. For example, using the exon-level expression profile data from the Gene Expression Omnibus (GEO) database, Yu et al, identified 617 alternatively spliced genes in GBM, information which may provide novel molecular markers for the diagnosis and treatment of GBM (Yu and $\mathrm{Fu}$ 2014). In another report, Sadeque et al, related alternative exon usage in 25,403 genes to the survival of 250 GBM patients and found that in 2,477 genes alternative exon usage was significantly associated with patient survival (Sadeque et al. 2012). Here we provide an overview of the published work which has indicated a role for alternative splicing in the initiation and/or progression of GBM. Specifically, we will highlight the alternatively spliced isoforms of the fibroblast growth factor receptor 1 (FGFR1), the gliomaassociated oncogene homolog 1 (Gli1), and the epidermal growth factor receptor (EGFR) as their contributions to the pathogenesis of GBM have been extensively characterized. 
Figure 1

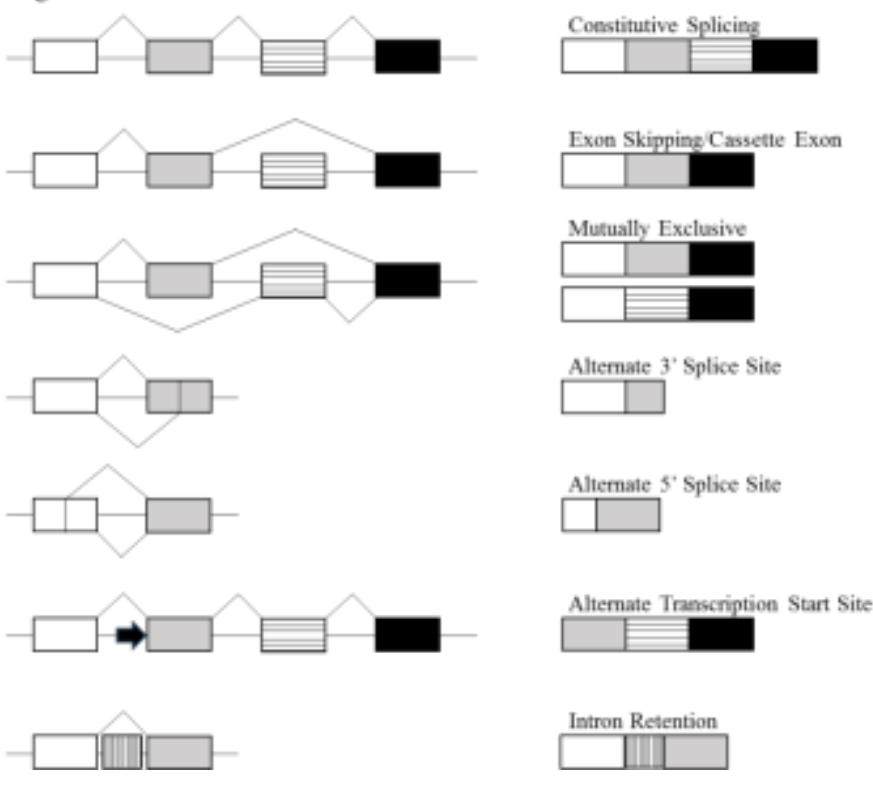

Figure 1. Modes of Alternative Splicing

Exons shown as boxes, introns as black lines. Arrow indicates alternate promoter. Splicing shown on left, resulting transcript on right.

\section{Alternative Splicing in the Pathogenesis of Glioma}

Tumorigenesis is a multistep process. It has been postulated that malignant growth is a manifestation of eight essential alterations in cell physiology which govern the transformation of normal human cells into malignant cancers: sustaining self-sufficiency, insensitivity to growth suppressors, evasion of programmed cell death, limitless replicative potential, sustained angiogenesis, tissue invasion, reprogramming of energy metabolism, and evasion of immune destruction (Hanahan and Weinberg 2000, 2011). More recently, it has been postulated that another fundamental characteristic of cancer cells, loss of terminal differentiation, should be considered a "hallmark" as well (Floor et al. 2012). It is becoming increasingly clear that aberrant alternative splicing plays a role in the regulation of many of these processes in GBM. In this section we present published examples of splicing isoforms relevant to some of these hallmarks of cancer that are functionally significant in the pathogenesis of GBM. Additionally, table 1 lists several examples of splice variants found to be present in GBM for which the function/mechanistic role is not yet characterized.

\subsection{Alternative Splicing in GBM Proliferation and Invasion}

One of the most fundamental traits of cancer cells involves their ability to sustain chronic proliferation. Attesting to uncontrolled cellular proliferation, there have been many examples from the literature indicating a role for alternative splicing in the proliferative capability of GBM. The first study we will examine describes the alternative splicing of KLF6 (Kruppel-like transcription factor). In this paper, authors demonstrate the existence of an allelic imbalance of KLF6 and its dominant negative splice isoform KLF6-SV1 in GBM. Here they show that the KLF6 tumor suppressor gene is reduced by $\sim 80 \%$ in GBM, while KLF6-SV1 is significantly increased. Importantly, targeted KLF6-SV1 knock-down in A235 glioma cells significantly decreased their cellular proliferation (Camacho-Vanegas et al. 2007). This effect is likely due to KLF6-SV1 antagonizing the full-length KLF6 protein, as is the case in prostate cancer (Narla, Difeo, Reeves, et al. 2005, Narla, DiFeo, Yao, et al. 2005).

In another study, alternative splicing was shown to inhibit the tumor suppressor function of the KAP protein and increase cellular proliferation through the generation of a dominant negative variant. The cyclin-dependent kinase-associated protein phosphatase, KAP, functions to dephosphorylate Cdk2 and inhibit cell cycle progression (Hannon, Casso, and Beach 1994). Unexpectedly, increased KAP mRNA expression was found in GBM, and its expression correlated with increased histological grade and decreased patient survival ( $\mathrm{Yu}$ et al. 2007). The paradoxical functioning of KAP in GBM was shown to be due to the aberrant alternative splicing of its transcript leading to the formation of several KAP mRNA splice variants containing deletions at exons 2 and 3. These splice variants were unable to generate the full length functional KAP protein and acted as dominant negatives against the fulllength KAP, ultimately promoting GBM proliferation ( $\mathrm{Yu}$ et al. 2007).

Having a role in several facets of tumorigenesis, alternative splicing of the human crk gene in GBM results in the aberrant expression of its isoform I. Crk was originally isolated as an oncogene product of the CT10 chicken retrovirus and has two alternatively spliced isoforms (Feller et al. 1998). While crkII is expressed in both normal cells and GBM, crkI is expressed at low levels in normal brain but is highly up-regulated in GBM. Authors compared the function of each isoform in glioma malignancy by transfecting U87 glioma cells with either CrkI or CrkII and examining the effect of each isoform on GBM phenotype. They found that expression of CrkI increased cellular transformation, migration, and invasion due to increased p130cas tyrosine phosphorylation and the ensuing activation of the FAK/p130cas/Crk/DOCK180 pathway (Takino et al. 2003).

The splicing factor, polypyrimidine tract-binding protein 1 (PTBP1/hnRNP I), plays a key role in alternative splicing by controlling the alternate 5' and 3' splice site usage (Hamid and Makeyev 2014). Binding adjacent introns or within exons themselves, PTBP1 represses the splicing of a large number of exons (Han et al. 2014). During development, PTBP1 and PTBP2 are expressed in glial and neuronal precursor cells respectively, and both transcripts decrease as cells differentiate to form the mature brain (Boutz et al. 2007). Importantly, 
PTBP1 is aberrantly overexpressed in GBM and may serve as a marker of progression (Cheung et al. 2006). In this next study, authors investigated PTBP1 overexpression in GBM. They found that PTBP1 specifically represses exon 3 expression in the RTN4 (Nogo) gene, resulting in decreased proliferation and invasion of glioma cells (Cheung et al. 2009).

PTBP1 has also been shown to mediate the alternative splicing of cassette exon 6 in the membrane-binding tumor suppressor annexin A7 (ANXA7) (Ferrarese et al. 2014). Reexpression of exon 6 by inhibition of PTBP1 increased endosomal targeting of EGFR, reduced angiogenesis and invasion, and ultimately reduced the malignancy of GBM (Ferrarese et al. 2014). Interestingly, in another study, inhibition of GSK3 $\beta$ with the small molecule inhibitor ARA014418 was shown to result in a time-dependent switch in alternative splicing from exon 6 exclusion to exon 6 inclusion in U87 and U373 glioma cells (Yadav et al. 2014). In this report, authors show a significant reduction in the splicing factors SRSF1, SRSF5, PTBP1, and hnRNPH3 upon GSK3 inhibition, likely mediating the ANXA7 alternative splicing switch. Although the direct targeting of aberrant alternative splicing will be discussed in greater length later in this review, this study suggests the importance of upstream effectors in alternative splicing and a mechanism for their subsequent inhibition.

Several reports have also linked alternative splicing of the tyrosine kinase receptor Recepteur d'Origine Nantais (RON) to GBM pathogenesis. RON $\Delta 11$ is a constitutively active isoform of the full length variant which lacks exon 11 and has been shown to promote cell motility and the epithelial-mesenchymal transition. Interestingly, exclusion of exon 11 has been attributed to at least two different regulatory splicing factors in GBM. Lefave, et al showed that RON $\Delta 11$ is significantly enhanced in GBM, and the overt exclusion of exon 11 was due to the regulatory splicing factor hnRNPH. HnRNPH was found increased in GBM and correlated with tumor grade. In vitro, its targeted inhibition decreased GBM invasiveness (Lefave et al. 2011). In another report, exon 11 skipping in RON was attributed to the splicing factor hnRNPA2/B1, which was also found to be significantly up-regulated in GBM and inversely correlated with patient survival (Golan- Gerstl et al. 2011). In this study, inhibition of RON expression in U87 glioma cells rescued hnRNPA2/B1-mediated increase in soft agar colony formation. The discrepancy in splicing factors mediating exon 11 exclusion may be due to the existence of multiple regulatory elements acting on the RON transcript, a collaboration between hnRNPH and hnRNPA2/B1, or an evolutionarily driven redundancy in the pathogenesis of GBM.

\subsection{Alternative Splicing in Terminal Differentiation}

Alternative splicing is often tissue-specific, and the production of multiple variants from a single gene frequently occurs in a developmental stage-specific manner. In the cancer stem cell concept, a small population of GBM cells behave similarly to normal stem cells in that they are able to self-renew and give rise to a variety of differentiated tumor cells (Campos et al. 2010). The RNA binding protein and splicing regulator A2BP1 (ataxin 2 binding protein 1, Rbfox1) is an alternative splicing factor that functions in neuronal development and is expressed exclusively in differentiated neurons. In this next study, authors show that A2BP1 is deleted and down-regulated in GBM and its loss contributes to tumorigenesis by compromising terminal differentiation ( $\mathrm{Hu}$ et al. 2013). It was shown that A2BP1 regulates the mutually exclusive splicing of exons $\mathrm{a}$ and $\mathrm{b}$ in the tumor suppressor TPM1, maintaining $\mathrm{a}$ high exon b/exon a ratio, and driving the neuronal differentiation of neural progenitor cells. Ectopic expression of TPM1-6b significantly suppressed intracranial tumor formation (Hu et al. 2013). Results from this study indicate that the immature differentiation state in GBM may be partly driven by a neutralization in the alternative splicing mechanisms which contribute to terminal differentiation.

\subsection{Alternative splicing in GBM Metabolism}

The ability for cancer cells to alter their metabolism to cope with hypoxia was first described by Otto Heinrich Warburg in 1956 (Warburg 1956a, b). The Warburg effect describes the increased uptake and conversion of glucose to lactate by cancer cells under adequate oxygen conditions, essentially foregoing oxidative phosphorylation for aerobic glycolysis. Aerobic glycolysis is partly regulated by the expression of pyruvate kinase isoforms, and there are several lines of evidence indicating that alternative splicing of pyruvate kinase is a critical determinant of the Warburg phenotype in GBM.

Pyruvate kinase catalyzes the final step in glycolysis, generating pyruvate and ATP. It is encoded by two paralagous genes, PK-L and PK-M, which each give rise to two alternatively spliced isoforms, $\mathrm{L}$ and $\mathrm{R}, \mathrm{M} 1$ and $\mathrm{M}$ 2, respectively (Jurica et al. 1998). The differentiated isoform of PK-M, PK-M1, promotes oxidative phosphorylation while the embryonic isoform, PK-M2, promotes aerobic glycolysis; the mutually exclusive alternative splicing of exons 9 and 10 in the PK-M pre-mRNA results in expression of PK-M1 (exon 9 included) or PK-M2 (exon 10 included) (David and Manley 2010, Chaneton and Gottlieb 2012).

Recent evidence has indicated that PK-M2 confers a selective growth advantage to tumor cells ( $\mathrm{Li}$, Yang, and $\mathrm{Li}$ 2014, Christofk et al. 2008). In a study by Clower, et al authors showed that shRNA mediated knock-down of the splicing factors hnRNPA1, hnRNPA2, and PTBP1 resulted in a significant increase in the PK-M1 isoform expression and a decrease in lactate production in GBM cells (Clower et al. 2010). Interestingly, it has been shown that all three of the aforementioned alternative splicing factors, PTBP1, hnRNPA1, and hnRNPA2 are overexpressed in GBM and their expression is directly attributable to the transcription factor c-Myc (David and Manley 2010). That neoplastic cells primarily express PKM2 over PK-M1 indicates a switch in the state of differentiation 
of these cells. Indeed, Clower et al show that when proliferating myoblasts are induced to terminally differentiate, there is a resultant almost exclusive switch from PK-M2 to PK-M1. It was interesting to note that of all the cancer tissues analyzed for PK-M isoform expression, only the two GBM lines tested showed evidence of both isoforms. This contradiction may be attributable to the remarkable heterogeneity of GBM.

Linking the GBM mutant EGFRvIII with alternative splicing in cellular metabolism, Babic, et al recently showed that expression of EGFRvIII in U87 glioma cells significantly increased the expression of hnRNPA1 (Babic et al. 2013). In this report, they show that hnRNPA1 mediates the alternative splicing of the myc-interacting protein Max, generating a truncated variant, Delta Max, whose overexpression increased GBM cell proliferation and promoted glycolytic gene expression in a Myc-dependent fashion (Babic et al. 2013). As EGFRvIII functionally synergizes with wtEGFR, it would be interesting to examine the ratio of PK-M1 to PK-M2 in GBM cells expressing both receptor types. It is possible that expression of PK-M1 in a subset of GBM cells confers a selective advantage to the tumor as a whole.

\subsection{Alternative Splicing in Apoptosis}

So far we have discussed aberrant splicing in the generation of variants which contribute to multiple aspects of GBM pathogenesis including tumor establishment, progression, and maintenance. In this next section we will discuss the role of aberrant alternative splicing in the molecular control of apoptosis, another hallmark of cancer. The death-domain adaptor protein Insuloma-Glucagonoma protein 20 (IG20) is consistently spliced to generate an antagonistic, anti- apoptotic isoform termed MADD (MAP-kinase activating death domain protein), which has exon 16 excluded. In this next study, authors show that while in normal brain there is equal expression of both IG20 and MADD isoforms, in GBM there is a switch from exon 16 inclusion to exon 16 exclusion forcing the expression of MADD. MADD has been shown to redirect
$\mathrm{TNFa}$ /TRAIL- induced death signaling to promote survival and proliferation instead of triggering apoptosis (Mulherkar, Prasad, and Prabhakar 2007). In this report, it is shown that exon 16 exclusion is mediated by the splicing factor hnRNPH, which is also upregulated in GBM (Lefave et al. 2011). Indeed, siRNA mediated inhibition of hnRNPH resulted in increased exon 16 inclusion along with an increase in apoptosis and reduction in cell viability, indicating the therapeutic potential of MADD neutralization (Lefave et al. 2011).

In addition, there have been several reports describing the up-regulation of the apoptosis inhibitor protein survivin and its isoforms survivin $\Delta \mathrm{Ex} 3$, survivin $2 \alpha$, survivin2B, survivin $3 \alpha$, and survivin3B in GBM. Virtually absent from normal differentiated cells, survivin is expressed in highly proliferative areas in normal tissues, including neural stem cells, and is expressed in virtually every human tumor (Caldas et al. 2005). The splice isoform survivin $\Delta \mathrm{Ex} 3$, which lacks exon 3 , has been shown to heterodimerize with survivin, and co-expression of these two variants protects medulloblastoma cells from apoptosis greater than expression of either variant alone (Caldas et al. 2005). Importantly, the ratio of survivin $\Delta E x 3$ to survivin was found to be significantly higher in malignant brain tumors, including GBM, compared to benign ones, and expression of survivin, survivin $2 \alpha$, and survivin2B increased with tumor grade (Yamada et al. 2003, Huang et al. 2011).

We have previously discussed the work by Golan-Gersti, et al who described the up- regulation of the hnRNPA2/B1 splicing factor in GBM (Golan-Gerstl et al. 2011). In this same report, authors also revealed a significant effect of hnRNPA2/B1 on the alternative splicing of caspase 9. They show that with high expression of hnRNPA2/B1 there is a significant increase in the exclusion of exons 3-6 in caspase 9, effectively forming the truncated mutant caspase-9b. Caspase$9 \mathrm{~b}$, acting as a dominant negative, blocks the activation of caspase-9 and -3 effectively inhibiting apoptosis and its expression in multiple cancer types has been reported (Srinivasula et al. 1999).

Table 1. Glioma Specific Isoforms

Isoforms identified specifically in GBM, with yet unknown or uncharacterized functional relevance.

\begin{tabular}{|c|c|c|c|c|}
\hline Gene & Splice Mechanism & Splice Variant & Function & Reference \\
\hline MDM4 & $\begin{array}{l}\text { Exon Exclusion: } \\
8,9\end{array}$ & MDM4-b & Negative regulator of p53 & (Wang et al. 2013) \\
\hline MDM2 & $\begin{array}{l}\text { Exon Exclusion: } \\
\text { ND }\end{array}$ & MDM2-splice & Negative regulator of p53 & (Kraus et al. 1999) \\
\hline MDM2 & $\begin{array}{l}\text { Exon Exclusion: } \\
\text { ND }\end{array}$ & MDM2-b & Negative regulator of p53 & (Matsumoto et al. 1998) \\
\hline
\end{tabular}




\begin{tabular}{|c|c|c|c|c|}
\hline SGK1 & $\begin{array}{l}\text { Alternate TSS: } \\
\text { Exon } 1 \\
\text { Intron } 3\end{array}$ & $\begin{array}{l}\text { SGK1.1 } \\
\text { SGK1.2 }\end{array}$ & $\begin{array}{l}\text { Regulator of transport, cell volume, } \\
\text { and cell survival }\end{array}$ & $\begin{array}{l}\text { (Simon et al. 2007, } \\
\text { Arteaga et al. 2008) }\end{array}$ \\
\hline RFX4 & $\begin{array}{l}\text { Exon Exclusion: } \\
1,6 \\
\text { Alternate TSS: } \\
\text { ND }\end{array}$ & $\begin{array}{l}\text { RFK4-D } \\
\text { RFX4-E } \\
\text { RFX4-F }\end{array}$ & Transcription Factor & (Matsushita et al. 2005) \\
\hline IIp45 & $\begin{array}{l}\text { Exon Exclusion: } \\
7\end{array}$ & IIp45S & Anti-invasion & (Song et al. 2005) \\
\hline CALD1 & $\begin{array}{l}\text { Exon Inclusion: } \\
1 \\
1+4 \\
1^{\prime}+4\end{array}$ & $\begin{array}{l}1 \\
1+4 \\
1 '+4\end{array}$ & $\begin{array}{l}\text { Cytoskeleton- } \\
\text { associated protein }\end{array}$ & $\begin{array}{l}\text { (Zheng, van der } \\
\text { Weiden, and Kros } \\
\text { 2005, Zheng et al. } \\
\text { 2004) }\end{array}$ \\
\hline $\mathrm{Ca}(\mathrm{v}) 3.1$ & $\begin{array}{l}\text { Exon Inclusion: } \\
25 \mathrm{a}, 26\end{array}$ & $\mathrm{Ca}(\mathrm{v}) 3.1 \mathrm{ac}$ & Calcium Channel & $\begin{array}{l}\text { (Latour et al. 2004, } \\
\text { Bertolesi et al. 2006) }\end{array}$ \\
\hline VEGF & $\begin{array}{l}\text { Exon Exclusion: } \\
6 \mathrm{a}, 6 \mathrm{~b}, 7 \\
6 \mathrm{a}, 6 \mathrm{~b} \\
6 \mathrm{~b}\end{array}$ & $\begin{array}{l}\text { VEGF121 } \\
\text { VEGF165 } \\
\text { VEGF189 }\end{array}$ & Angiogenesis & $\begin{array}{l}\text { (Huang et al. 2005, } \\
\text { Cheng et al. 1997) }\end{array}$ \\
\hline MAP-2 & $\begin{array}{l}\text { Exon Inclusion/ } \\
\text { Exclusion: } \\
\text { 13/7a-8 }\end{array}$ & MAP-2e & Development & (Suzuki et al. 2002) \\
\hline HdynIV & $\begin{array}{l}\text { Exon Exclusion: } \\
15\end{array}$ & HydnIV-26 & $\begin{array}{l}\text { Endocytosis and } \\
\text { Vesicle Trafficking }\end{array}$ & $\begin{array}{l}\text { (Chen et al. 2000, Chen } \\
\text { et al. 2003) }\end{array}$ \\
\hline V1 & $\begin{array}{l}\text { Exon Inclusion: } \\
7\end{array}$ & V0 & $\begin{array}{l}\text { Chondroitan sulfate } \\
\text { proteoglycan }\end{array}$ & $\begin{array}{l}\text { (Dours-Zimmermann } \\
\text { and Zimmermann 1994) }\end{array}$ \\
\hline RTVP-1 & $\begin{array}{l}\text { Exon Inclusion: } \\
71 \text { bp deletion between } 2 \\
\& 3\end{array}$ & RTVP-1b & Pathogenesis & (Xiang et al. 2007) \\
\hline RSU-1 & $\begin{array}{l}\text { Exon Exclusion: } \\
\text { 133bp deletion }\end{array}$ & $\begin{array}{l}\text { Exon-deleted } \\
\text { RSU-1 }\end{array}$ & Tumor suppressor & (Chunduru et al. 2002) \\
\hline
\end{tabular}

Abbreviations-MDM, mouse double minute; KLF, Krüppel like factor; SGK, serum- and glucocorticoid-inducible kinase 1; ADAM, a disintegrin and metalloproteinase domain; RFX4, Regulatory Factor X4; IIp45, Invasion Inhibitory Protein 45; CALD1, Caldesmon; Ca(v)3.2, T- type calcium-channel; VEGF, Vascular Endothelial Growth Factor; MAP-2, Microtubule- associated protein-2; HdynIV, Dynamin-like protein; V1, versican; RTVP, related to testes- specific, vespid, and pathogenesis protein; RSU-1, Ras suppressor protein 1, ND, Not Determined; TSS, Transcription Start Site

\section{Alternative Splicing of FGFR}

Alternative splicing leading to the differential expression of the fibroblast growth factor receptor (FGFR) has been shown to play a critical role in the malignant progression of GBM. The FGFR family is composed of four different receptors, FGFR1 FGFR4, with several alternatively spliced variants of FGFR1 and FGFR2 (Werner et al. 1993). Increased expression of
FGFR1 in GBM is often accompanied by a shift in its splicing pattern, with FGFR $1 \beta$ as the predominant isoform (Yamaguchi et al. 1994). Compared to FGFR1 $\alpha$, FGFR1 $\beta$, lacking exon 3 (alpha exon), has an increased affinity for ligand due to the absence of one of the three extracellular NH2- terminal loops and its expression results in a cell-growth advantage, contributing to GBM malignancy (Yamada et al. 1999, Wang, 
Kan, Yan, et al. 1995, Wang, Kan, Xu, et al. 1995, Loilome et al. 2009).

A good deal of progress has been made in understanding the molecular mechanisms behind the aberrant alternative splicing switch from FGFR $1 \alpha$ to FGFR $1 \beta$ since its discovery.

Interestingly, FGFR1 contains two repressor elements capable of inhibiting exon 3 recognition, one downstream and one upstream, which are functionally redundant and exhibit significant sequence homology (Jin et al. 1998, 1999). The splicing factor PTBP1, whose expression is strongly increased in tumor tissue compared to adjacent normal brain, has been shown to be one of the regulators of FGFR1 splicing by specifically binding the ISS-1 regulatory element in the intron upstream of exon 3 (Jin et al. 2000). Use of antisense RNA oligonucleotides to target the ISS-1 regulatory element inhibited PTBP1 binding and enhanced endogenous exon 3 inclusion (Jin et al. 2003).

Importantly, another study in which authors used antisense morpholino oligonucleotides to target the ISS flanking exon 3 of FGFR1 described an increase in caspase-3 and -7 in U251 glioma cells, without affecting cell viability (Bruno, Jin, and Cote 2004). It is noteworthy that use of the oligonucleotides increased exon 3 inclusion from $10 \%$ to $70 \%$ in vivo, making this a strong therapeutic candidate for use in GBM patients. The use of oligonucleotides as a therapy for targeting alternative splicing events will be discussed more thoroughly later in this review.

\section{Alternative Splicing of GLI-1}

The glioma-associated oncogene homologue 1 (GLI1) is a member of the GLI transcription factors which are the main effectors of the Sonic Hedgehog (shh) pathway. Addition of shh ligand to cells, activates a signaling cascade leading to the translocation of GLI to the nucleus enabling the transcription of several genes including GLI1 (Carpenter and Lo 2012, Cui et al. 2010). GLI1 was first identified in 1987 as it was highly upregulated in a GBM tumor (Kinzler et al. 1987). Since then, it has been shown that GLI1 undergoes alternative splicing resulting in the expression of several different splice variants, including GLI1 $\Delta \mathrm{N}$ and tGLI1 (Wang and Rothnagel 2001). While GLI $1 \Delta \mathrm{N}$ is prevalent in both normal and cancerous tissues and behaves similarly to the full length GLI1, tGLI1, although absent in normal tissue, is highly expressed in GBM and other cancers (Carpenter and Lo 2012, Lo et al. 2009, Shimokawa et al. 2008).

The tGLI1 isoform is a truncated splice variant with exon 3 and part of exon 4 deleted (Lo et al. 2009, Zhu et al. 2014). While tGLI1 undergoes nuclear translocation similar to fulllength GLI1 (GLI1FL), there are more than 100 genes differentially expressed between the two. Importantly, tGLI1 was shown to bind CD24 with a significantly greater affinity than GLI1, and the subsequent transcriptional activation of CD24 by tGLI1 increased the migration and invasion of U87 GBM cells (Lo et al. 2009). Furthermore, expression of tGLI1 has been directly linked to enhanced tumor growth and vascularity of GBM xenografts (Zhu et al. 2014). In this report, authors show that tGLI1-expressing GBM xenografts were more aggressive in growth, with higher microvascular density, and increased Ki-67 positive cells than in the control. Further supporting its role as a novel mediator of neoangiogenesis, tGLI1-expressing tumor cells strongly up- regulated VEGFA and heparanase promoting increased tubule formation of vascular endothelial cells and increased the angiogenesis of chick embryos in vivo (Zhu et al. 2014). Interestingly, GLI1FL has been shown to mediate resistance to chemotherapy in GBM, however the effects of GLI1 variants in this realm have not yet been reported (Cui et al. 2010).

\section{Alternative Splicing of EGFR}

The epidermal growth factor receptor (EGFR) is a transmembrane glycoprotein whose dimerization upon ligand binding results in its autophosphorylation and activation (Ogiso et al. 2002). While amplification of EGFR is the most common genetic aberration associated with GBM, it is also among the most frequently mutated genes and maintains a diversity of altered transcripts. The most common mutant form associated with GBM is EGFRvIII, although a variety of other recurrent non-canonical EGFR transcript forms have been detected. In a recent report, 57\% of 164 RNA samples from GBM patients showed evidence of mutation, rearrangement, altered splicing and/or focal amplification of EGFR (Brennan et al. 2013). Interestingly, nearly all EGFR mutations have been detected in tumors with EGFR amplification and multiple types of EGFR mutations can be detected in individual tumors attesting to the heterogeneity of GBM (Pines et al. 2010, Frederick et al. 2000).

The EGFR gene is located at chromosome 7p12 and contains 28 exons transcribed into a protein with three distinct domains: extracellular (ECD), transmembrane (TMD), and intracellular (ICD). There are five common mutants, EGFRvI EGFRvV. Mutants EGFRvII, EGFRvIII and EGFRvIV have entire exons deleted, while EGFRvI and EGFRvV have NH2terminal and $\mathrm{COOH}$ - terminal truncations, respectively (Figure 2) (Nicholas et al. 2006). EGFRvI and EGFRvIV are rare, while EGFRvII and EGFRvV are marginally more common, each accounting about $10 \%$ of all GBM-associated EGFR mutations (Kastenhuber et al. 2014). While functional analyses of mutant EGFRvIII have been well-characterized, the same cannot be said for other EGFR mutants, likely attributable to their frequent cooccurrence with EGFRvIII. However, some studies have begun to tease apart the functional relevance of each mutant, and these are summarized below.

We will begin by discussing the EGFR ECD mutants EGFRvI, EGFRvII, and EGFRvIII. EGFRvI has an extensive Nterminal truncation comprising almost the entire extracellular domain. Resembling the viral erbB oncogenic protein, in GBM this mutant is constitutively active independently of ligand (Voldborg et al. 1997, Humphrey et al. 1988, Wong et al. 1992), however the functional relevance of this variant in GBM pathogenesis remains unclear. 
The EGFRvII mutant bears an in-frame deletion from amino acids 520-603 within domain IV of the ECD. This mutant is capable of high affinity ligand binding, resulting in its activation. It responds to growth factors in a similar fashion as wtEGFR: treatment with EGF results in enhanced tyrosine kinase autophosphorylation, increasing cellular proliferation and invasion in vitro (Humphrey et al. 1991). However, its constitutive phosphorylation, indicative of ligand- independent activation, has also recently been described (Francis et al. 2014). Indeed, expression of the EGFRvII variant in E14.5 neural stem cells revealed its constitutive phosphorylation along with an increased capacity to form subcutaneous tumors in nude mice when compared to cells expressing wtEGFR (Francis et al. 2014).

By far the most common mutant, EGFRvIII arises through an in-frame deletion of $801 \mathrm{bp}$ from the EGFR ECD due to the genomic deletion of exons 2-7. Its effects on glioma pathogenicity have been well-characterized, and are primarily attributable to its constitutively low level of activation and defective receptor internalization (Huang et al. 1997). The effect of EGFRvIII expression in promoting the tumorigenicity of GBM xenografts has been extensively documented. Originally attributed to an increase in proliferation along with a reduction in apoptosis due to an up-regulation of Bcl-XL, EGFRvIII has since been shown to stimulate GBM invasion, play key roles in mediating chemo- and radio-therapy resistance in GBM, and contribute to GBM heterogeneity (Nishikawa et al. 1994, Nagane et al. 1996, Nagane et al. 1998, Nagane et al. 2001, Lu et al. 2009, Inda et al. 2010, Nathanson et al. 2014, Feng et al. 2014).

Less frequently mutated in GBM, two EGFRvIV mutants have been described with deletions in the ICD: EGFRvIVa which lacks exons 25-27 and EGFRvIVb which lacks exons 25 and 26 (Kuan, Wikstrand, and Bigner 2001). The EGFRvIV mutants show constitutive dimerization and autophosphorylation, independently of ligand. Subcutaneous implantation of U87 cells expressing either EGFRvIV, EGFRvIII or wtEGFR in mice, revealed an increase in tumorigenicity in cells expressing EGFRvIV compared to wtEGFR, although to a lesser extent than EGFRvIII (Pines et al. 2010).

The mutant EGFRvV is a C-terminal truncated EGFR which has been reported to show increased ligand-dependent kinase activity and signaling along with a deficiency in internalization (Chen et al. 1989). Additionally, it maintains a much broader substrate specificity than wtEGFR (Decker, Alexander, and Habib 1992).

Cho et al, recently characterized the prevalence and oncogenic potential of EGFR C- terminal domain (CTD) mutants, including EGFRvIV and EGFRvV. An analysis of 469 GBM samples from the TCGA data for the presence of Cterminal exonic deletions confirmed the presence of three different C-terminal deletions of EGFR: exons 25-28 (EGFRvV), exons 25-27 (EGFRvIV), and exon 27 (Cho et al. 2011). Forced expression of each EGFR-CTD mutant in $\mathrm{Ba} / \mathrm{F} 3$ cells promoted IL3 independent growth, demonstrating oncogenic function and EGF ligand-independent receptor autophosphorylation. Importantly, expression of EGFR-CTD mutants in LN443 GBM cells significantly increased their tumorigenicity in an intracranial mouse model compared to control (Cho et al. 2011).

While the EGFRvI-vV mutants have been the most frequently reported, many other mutants exist due to missense, duplication-insertion or other in-frame deletions. For example, EGFRvVI and EGFRvVII are EGFR mutants that are composites of EGFRvIII plus EGFRvIV or EGFRvV deletions, and the existence of a double mutant EGFRvIII with an additional deletion at exons 12-13, EGFRvIII/ 12 -13, has been reported (Kuan, Wikstrand, and Bigner 2001). Additionally, the existence of a mutant EGFR harboring a deletion from exons 1316, denoted EGFRvII-extended, has recently been described (Francis et al. 2014). It has been hypothesized that alternative splicing may play a role in the expression of these mutant EGFR variants. For example, sequencing cDNA from the EGFR mutant deleted for exon 27 confirmed transcription of an aberrant mRNA, consistent with splicing between exons 26 and 28 (Cho et al. 2011). Future studies are warranted to determine to which splicing factor this may be attributed.

Aside from the common EGFR mutants, the existence of alternative EGFR transcript mRNAs has been described (Reiter et al. 2001, Reiter and Maihle 1996). For example, Piccione et al describe the identification and characterization of mLEEK, a novel EGFR variant deleted at exons 2-22 and overexpressed in GBM (Piccione et al. 2012). siRNA-mediated knock-down of mLEEK dramatically reduced cell viability corresponding to a significant induction in caspase- 3 and -7 activity. It was reported that mLEEK is produced in the absence of genomic rearrangement and amplification, therefore alternative splicing may be attributable to its formation (Piccione et al. 2012). Along these same lines, EGFRvIII has been detected in a number of non-glioma tumors devoid of gene amplification or rearrangement and it has been suggested that alternative splicing also contributes to its formation (Okamoto et al. 2003). Specifically, the EGFRvIII mutant has been predicted to occur through the splice joining of exons 1-8 (Pedersen et al. 2001, Sugawa et al. 1990, Schwechheimer, Huang, and Cavenee 1995). Another example which designates alternative splicing in the formation of EGFR variants is in the case of the EGFR variant de4 EGFR. In this report, de4 EGFR was identified as an EGFR mutant with an aberrant splice joining of exons 3 and 5 and was expressed in 4/40 glioma tissues examined (Wang et al. 2011). Similar to other EGFR mutants, de4 EGFR is intrinsically constitutively activated with a low basal tyrosine phosphorylation due to its ability to self-dimerize in the absence of ligand. Overexpression of de4 EGFR in U87 glioma cells resulted in increased proliferation, anchorage-independent colony formation, migration, and invasion (Wang et al. 2011).

All of the EGFR mutants discussed thus far exist as transmembrane proteins. Soluble EGFR (sEGFR) isoforms are comprised solely of the extracellular domain, and are genuine 
variants generated by alternative splicing. Specifically, sEGFR isoforms b, c, and d are encoded by the EGFR mRNA variants v2, v3, and v4 (Guillaudeau, Durand, Bessette, et al. 2012).

These isoforms have been detected in both normal and malignant cells including adenocarcinoma, breast cancer, and ovarian cancer (Perez-Torres et al. 2008, Baron et al. 2009). And more recently EGFRv2, v3, and v4 transcripts were shown to be expressed in GBM in addition to the full length wtEGFR and mutant EGFRvIII. Although their functional relevance in GBM has not yet been investigated, these variant mRNA transcripts were significantly increased in GBM tissues which had wtEGFR amplification (Guillaudeau, Durand, Rabinovitch-Chable, et al. 2012).

\section{Figure 2}

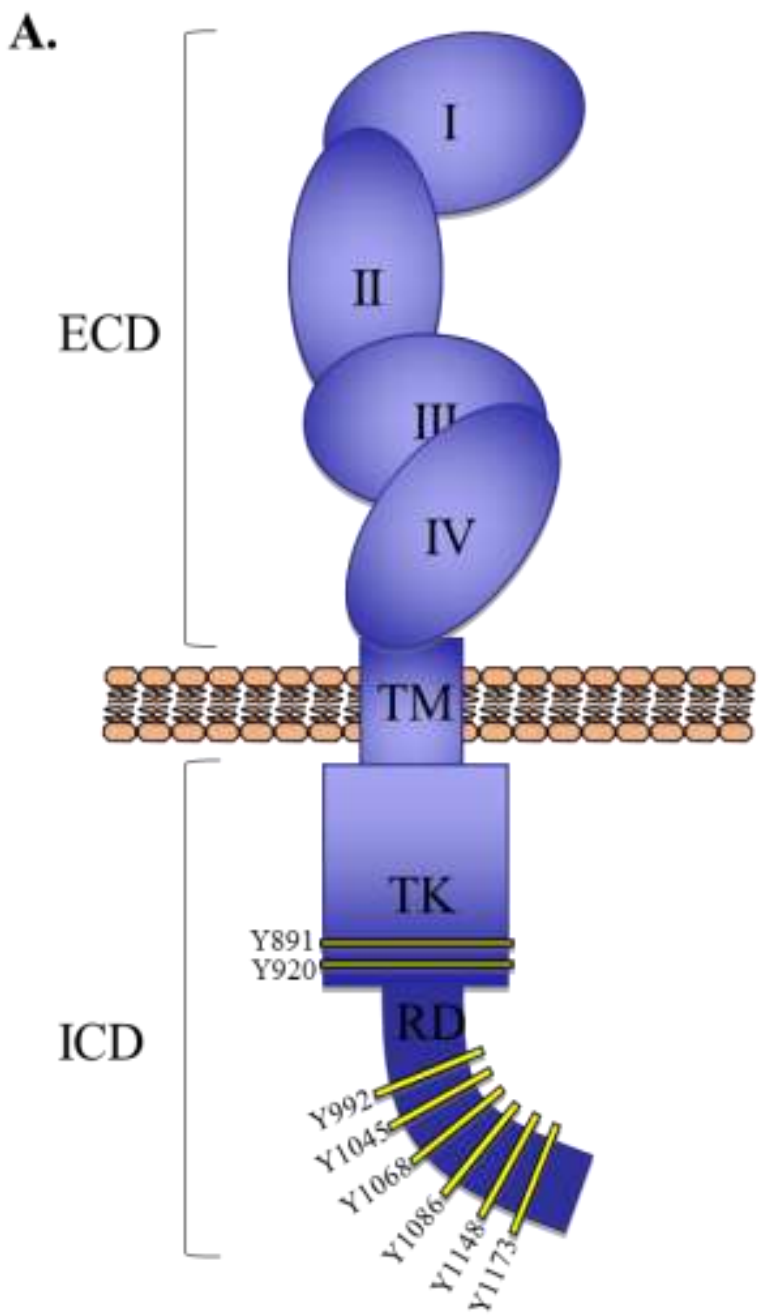

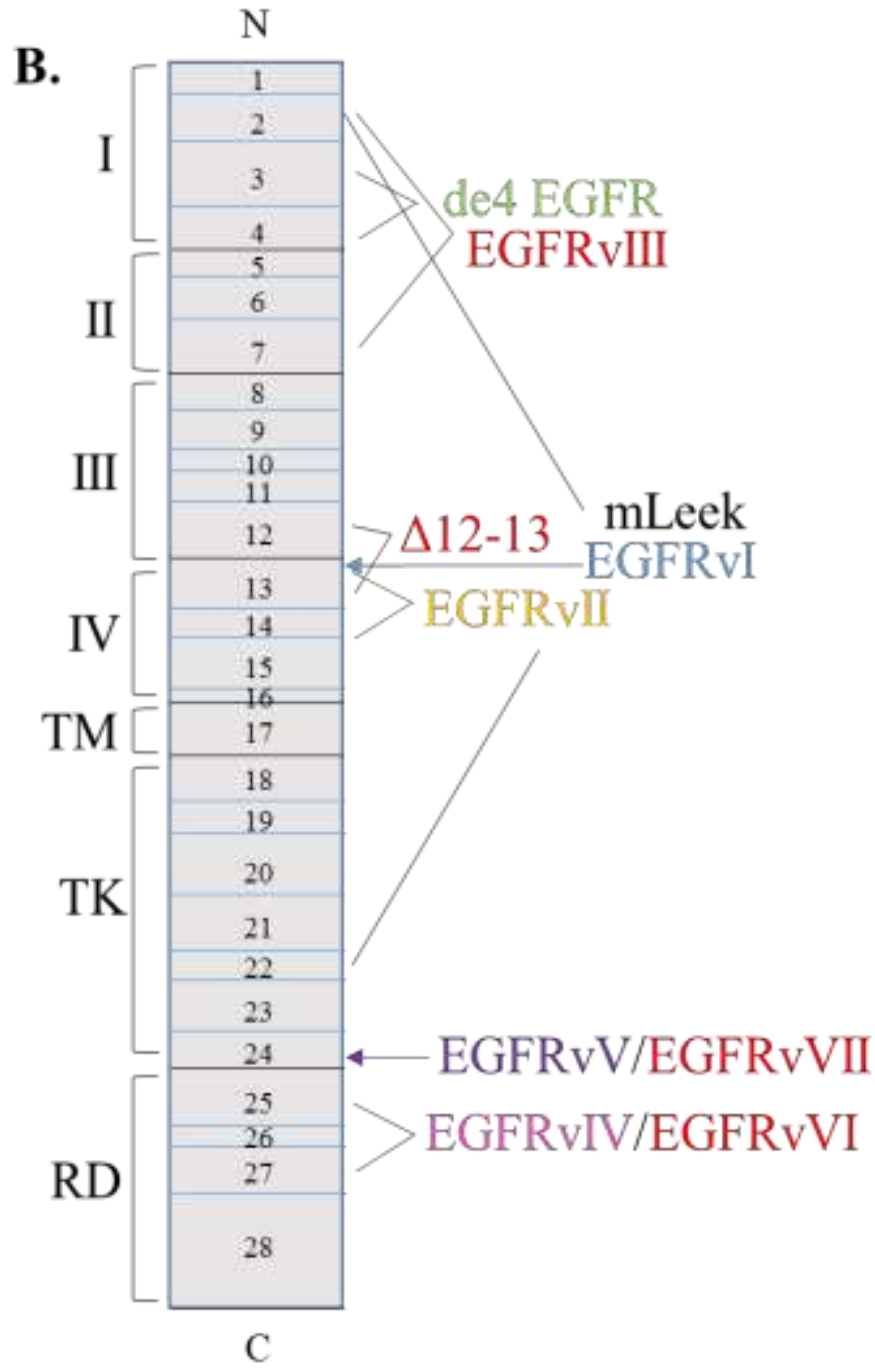

Figure 2: EGFR Organization and Mutants

A. Schematic depicting the EGFR protein at the cell surface. Y891-Y1173 indicate tyrosine phosphorylation sites.

B. Location of mutants within the EGFR protein composed of exons 1-28. Deletion mutants co-occurring with EGFRvIII are in red. de4 EGFR - exon 3-5 splice joining; EGFRvIII - exon 2-7 deletion; mLEEK - exon 2-22 deletion; EGFRvI - N-542 $\mathrm{NH}_{2}$ - terminal truncation; EGFRvII exon 14-15 deletion; EGFRvV - C-958 COOH-terminal truncation; EGFRvIV - exon 25-27 deletion. EGFRvVII - EGFRvIII + EGFRvV composite; EGFRvVI - EGFRvIII + EGFRvIV composite; EGFRVIII/412-13 - EGFRvIII + exon 12-13 deletion. I, II, III, and IV indicate subdomains. ECD: Extracellular Domain, ICD: Intracellular Domain, TM: Transmembrane, TK: Tyrosine Kinase, RD: Regulatory/Phosphorylation Domain. 


\section{Alternatively Spliced Variants as Therapeutic Agents}

The exploitation of aberrant alternatively spliced variants for use as novel therapeutic agents against GBM has been well-documented. In this section, we will describe several studies in which alternatively spliced variants, acting as dominant negatives, have been utilized as a therapeutic modality. We will also discuss the use of antisense oligonucleotides and monoclonal antibodies that specifically target alternatively spliced isoforms.

The Receptor for Advanced Glycation End-products (RAGE) is a multi-ligand receptor expressed at high levels in GBM (Tafani et al. 2011). Its expression leads to the activation of several downstream signaling pathways involved in cell proliferation, survival, differentiation, migration, phagocytosis, and autophagy (Chen et al. 2014). Previous studies have shown that the ICD of RAGE is essential for its activation. Indeed, Taguchi et al, have shown that ectopic expression of a truncated RAGE mutant lacking the cytosolic tail acts as a dominant negative against RAGE signaling (Taguchi et al. 2000). In this report, expression of the tail-deleted mutant RAGE in C6 glioma cells resulted in a significant suppression of cellular proliferation, invasion, migration, and tumorigenicity. While the alternative splicing of RAGE has been extensively documented (Park et al. 2004, Hudson et al. 2008), only recently has an endogenous truncated RAGE (RAGE $\Delta \mathrm{ICD}$ ) been identified. Ectopic expression of the RAGE $\triangle \mathrm{ICD}$ splice variant in C6 glioma cells reduced MAPK signaling, decreased cell motility, and decreased invasiveness compared to cells expressing the full length RAGE (Jules, Maiguel, and Hudson 2013). Additionally, cells expressing RAGE $\triangle I C D$ showed a reduction in proliferation and anchorage- independent colony formation compared to control. This study reveals the existence of an endogenously spliced truncated RAGE isoform which acts as a dominant negative against the tumorigenic effects of full-length RAGE.

The endogenous truncated variant of scatter factor/hepatocyte growth factor (SF/HGF), referred to as HGF/NK2, is another example of an alternatively spliced variant which may be exploited to antagonize growth factor signaling in GBM. SF/HGF, which binds the receptor c-met, has been shown to play key roles in glioma pathogenesis, such as increasing invasion, migration, inflammatory cell recruitment, and angiogenesis (Hamasuna et al. 1999, Badie et al. 1999, Lamszus et al. 1998, Moriyama et al. 1998, Laterra et al. 1997). Secretion of its splice variant HGF/NK2 has been projected to function in a dominant negative manner through its high-affinity binding to the c-met receptor, disrupting the autocrine signaling of SF/HGF (Chan et al. 1991). Indeed, investigating the effect of HGF/NK2 expression in GBM malignancy, authors show that its expression in U87 glioma cells inhibits colony formation and reduces migration in vitro, while reducing intracranial growth in vivo (Guerin et al. 2000).

In another example, the heparanase splice variant 36, originally cloned from the subterranean blind mole rat, Spalax, was also shown to act as a dominant negative to wild type heparanase. Heparanase is highly expressed in GBM and its overexpression results in a significant increase in migration, invasion, proliferation, and anchorage-independent colony formation in U251 glioma cells (Hong et al. 2010, Hong et al. 2008). Interestingly, expression of splice variant 36 in U87 glioma cells subcutaneously implanted in mice resulted in a significant reduction in tumor formation compared to control (Nasser et al. 2009).

The differential potency of alternatively spliced Bim variants is exemplified in a study by Yamaguchi et al, who found that the splice variant BimS was more effective at combatting GBM through gene therapy than BimL or BimEL. $\mathrm{Bim}$ is a pro-apoptotic BH3-only member of the $\mathrm{Bcl}-2$ superfamily which is spliced into several different isoforms, including BimEL, BimL and BimS

(Yamaguchi et al. 2003). Of these, BimS is considerably more cytotoxic as it does not bind LC8, a component of the microtubule-associated dynein motor complex, and is therefore free to neutralize anti-apoptotic Bcl-2 members (Puthalakath et al. 1999). Indeed, glioma cells infected with adenovirus vectors expressing BimS (AVC2-BimS) were significantly more apoptotic than cells infected with AVC2-BimL or AVC2BimFL. Furthermore, the combined injection of AVC2- BimS with AVC2-tk (an adenovirus expressing the herpes simplex virus thymidine kinase) markedly increased the sensitivity of U251 glioma cells to ganciclovir, as indicated by reduced in vivo tumor growth (Yamaguchi et al. 2003). The results from this study reveal the possibility of exploiting alternatively spliced variants in gene therapy for GBM.

Next we will discuss the use of antisense oligonucleotides and monoclonal antibodies to target specific protein variants which are aberrantly expressed and contribute to the pathogenesis of GBM. We previously discussed the aberrant alternative splicing of pyruvate kinase in GBM wherein exclusion of exon 9 generates the embryonic isoform PK-M2 important in aerobic glycolysis and tumor growth (Clower et al. 2010). Using an antisense oligonucleotide which specifically targets a novel enhancer in exon 10, authors of this next study were able to experimentally induce a switch in the splicing of endogenous PK-M transcripts to include exon 9. Inclusion of exon 9 down-regulated the expression of PK-M2 and increased apoptosis in GBM cell lines (Wang et al. 2012).

In another study, use of an antisense morpholino oligonucleotide treatment effectively reversed the aberrant splicing of USP5 by PTBP1. In this study, USP5 was identified as a novel target of PTBP1 whose increased expression, as in GBM and discussed previously (Cheung et al. 2009, Han et al. 2014), resulted in the aberrant generation of USP5 isoform 2. Using an antisense morpholino oligonucleotide which targets the 5' splice site of exon 15 in USP5 resulted in a dramatic switch from isoform 2 to isoform 1 in both U251 and LN229 GBM cell lines. Importantly, the forced expression of USP5 isoform 1 inhibited glioma cell growth and migration indicating an important role for USP5 splicing in GBM pathogenesis (Izaguirre et al. 2012). The results from these studies reveal the 
potential for antisense morpholino oligonucleotides as a novel therapy for GBM.

Lastly, the generation of recombinant antibodies to specifically target splice variants involved in GBM pathogenesis has been a novel approach to selectively target tumor cells. Monoclonal antibodies (mAbs) targeting splice isoforms of Tenascin- $\mathrm{C}$ have been used in the clinic to deliver radioactive isotopes to GBM tumors for diagnostic and therapeutic purposes (Zalutsky et al. 1989). Tenascin-C is an extracellular matrix glycoprotein whose primary transcript is alternatively spliced, resulting in the generation of two main isoforms, small and large, with distinct biological functions. Specifically, the large isoform, which has been shown to confer loss of focal adhesion in cultured cells, is highly expressed in GBM and two mAbs, BC-2 and 81C6, which both specifically target the large isoform, have shown promise in the clinic (Borsi et al. 1994, Carnemolla et al. 1999, Reardon et al. 2002). Other anti-tenascin-c antibodies have been generated which may have greater selectivity for GBM tumor tissues including TN11, which specifically recognizes the type III repeat $C$ of the large Tenascin-C isoform, and $\operatorname{SIP}(\mathrm{F} 16)$, specific to the alternatively spliced domain A1 of tenascin-C (Carnemolla et al. 1999, Brack et al. 2006).

Along these same lines, the mAb 806 specifically targets the mutant EGFRvIII and has shown significant anti-tumoral activity in human xenograft mouse models. Treatment of mice bearing intracranial EGFRvIII expressing U87 gliomas with $\mathrm{mAb} 806$, resulted in a significant reduction in EGFRvIII autophosphorylation, decreased angiogenesis, and increased apoptosis compared to untreated tumors (Mishima et al. 2001). Importantly, these effects have been shown to be specific to cells expressing EGFRvIII or amplification of the EGFR gene, as $\mathrm{mAb} 806$ had no bearing on normal wtEGFR expressing cells (Luwor et al. 2001). Use of a mAb 806 chimera in a Phase I clinical trial for patients with diverse tumor types revealed it was well-tolerated and specifically targeted the tumor site (Scott et al. 2007). Several other Phase I clinical trials measuring the safety, pharmacokinetics, biodistribution and imaging characteristics of $\mathrm{mAb}$ ABT-806 and ABT-806i, an indium-labeled conjugate of ABT-806, are currently underway (www.clinicaltrials.gov).

Administration of mAbs targeting tumor-specific isoforms expressed by GBM is an innovative therapeutic strategy that should be further examined in the clinic. Taken together, these studies indicate the potential to harness alternative splicing as a novel means to control oncogenic function, combatting GBM.

\section{CONCLUSIONS}

Alternative pre-mRNA splicing is an important mechanism in gene regulation. The alteration of alternative splicing in GBM may be used in the identification and characterization of glioma-specific splice variants that can be used as novel diagnostic and prognostic tumor biomarkers and potential targets for therapy. That aberrant alternative splicing is so widely recognized in cancer biology, indicates that it may drive potential escape mechanisms in the cancer cell. For example, compared to cells maintained in normal oxygen, T98G glioma cells maintained in a low oxygen environment show increased expression of the alternatively spliced isoform of the human prion protein $(\mathrm{PrP})$, with a concomitant decrease in the normally spliced PrP transcript (Kikuchi et al. 2008). Further studies are warranted to investigate a role for alternative splicing in mechanisms of escape which may drive therapeutic resistance and tumor relapse.

The potential to reverse alternative splicing, in the absence of deletion, suggests a response to extracellular cues, enabling the adaptation of cells to changing environmental conditions. Several of the studies we discussed, and many of the variants listed in table 1, reveal a correlation between alternative splicing and tumor grade. One may postulate then that as a tumor grows, increasing in vascularity, with expanding hypoxic niches and further invading the brain, the ever- changing tumor microenvironment contributes to a disruption in the normal mRNA splice pattern. The remarkable heterogeneity of GBM may indeed be a facet of environmentally induced alternative splicing. It is interesting to hypothesize a role for alternative splicing in the generation of many different transcripts from the same gene, whose protein expression is effected simply by the location of the cell within which it resides. It is important to keep in mind, however, that it is the aberrant expression of splicing factors which generate aberrant splice forms. Ultimately a more thorough understanding of the regulation of these factors will be necessary to truly define a global role for alternative splicing in GBM.

\section{ACKNOWLEDGEMENTS}

This work was supported by the Defeat GBM Research Collaborative, a subsidiary of the National Brain Tumor Society (WKC, FBF), and by a T32 training grant from the NIH 2T32CA009523-29A1 (AHT). 


\section{REFERENCES}

Arteaga, M. F., T. Coric, C. Straub, and C. M. Canessa. 2008. "A brain-specific SGK1 splice isoform regulates expression of ASIC1 in neurons." Proc Natl Acad Sci U S A 105 (11):4459-64. doi: 10.1073/pnas.0800958105.

Babic, I., E. S. Anderson, K. Tanaka, D. Guo, K. Masui, B. Li, S. Zhu, Y. Gu, G. R. Villa, D. Akhavan, D. Nathanson, B. Gini, S. Mareninov, R. Li, C. E. Camacho, S. K. Kurdistani, A. Eskin, S. F. Nelson, W. H. Yong, W. K. Cavenee, T. F. Cloughesy, H. R. Christofk, D. L. Black, and P. S. Mischel. 2013. "EGFR mutation-induced alternative splicing of Max contributes to growth of glycolytic tumors in brain cancer." Cell Metab 17 (6):1000-8. doi: 10.1016/j.cmet.2013.04.013.

Badie, B., J. Schartner, J. Klaver, and J. Vorpahl. 1999. "In vitro modulation of microglia motility by glioma cells is mediated by hepatocyte growth factor/scatter factor." Neurosurgery 44 (5):1077-82; discussion 1082-3.

Baron, A. T., J. A. Wilken, D. E. Haggstrom, S. T. Goodrich, and N. J. Maihle. 2009. "Clinical implementation of soluble EGFR (sEGFR) as a theragnostic serum biomarker of breast, lung and ovarian cancer." IDrugs 12 (5):302-8.

Bertolesi, G. E., R. Walia Da Silva, C. A. Jollimore, C. Shi, S. Barnes, and M. E. Kelly. 2006. "Ca(v)3.1 splice variant expression during neuronal differentiation of Y79 retinoblastoma cells." Neuroscience 141 (1):259-68. doi: 10.1016/j.neuroscience.2006.03.067.

Borsi, L., E. Balza, P. Castellani, B. Carnemolla, M. Ponassi, G. Querze, and L. Zardi. 1994. "Cell-cycle dependent alternative splicing of the tenascin primary transcript." Cell Adhes Commun 1 (4):307-17.

Boutz, P. L., P. Stoilov, Q. Li, C. H. Lin, G. Chawla, K. Ostrow, L. Shiue, M. Ares, Jr., and D. L. Black. 2007. "A post-transcriptional regulatory switch in polypyrimidine tract-binding proteins reprograms alternative splicing in developing neurons." Genes Dev 21 (13):1636-52. doi: 10.1101/gad.1558107.

Brack, S. S., M. Silacci, M. Birchler, and D. Neri. 2006. "Tumor-targeting properties of novel antibodies specific to the large isoform of tenascin-C." Clin Cancer Res 12 (10):3200-8. doi: 10.1158/1078-0432.CCR-05-2804.

Brennan, C. W., R. G. Verhaak, A. McKenna, B. Campos, H. Noushmehr, S. R. Salama, S. Zheng, D. Chakravarty, J. Z. Sanborn, S. H. Berman, R. Beroukhim, B. Bernard, C. J. Wu, G. Genovese, I. Shmulevich, J. Barnholtz-Sloan, L. Zou, R. Vegesna, S. A. Shukla, G. Ciriello, W. K. Yung, W. Zhang, C. Sougnez, T. Mikkelsen, K. Aldape, D. D. Bigner, E. G. Van Meir, M. Prados, A. Sloan, K. L. Black, J. Eschbacher, G. Finocchiaro, W. Friedman, D. W. Andrews, A. Guha, M. Iacocca, B. P. O'Neill, G. Foltz, J. Myers, D. J. Weisenberger, R. Penny, R. Kucherlapati, C. M. Perou, D. N. Hayes, R. Gibbs, M. Marra, G. B. Mills, E. Lander, P. Spellman, R. Wilson, C. Sander, J. Weinstein, M. Meyerson, S. Gabriel, P. W. Laird, D. Haussler, G. Getz, L. Chin, and Tcga Research Network. 2013. "The somatic genomic landscape of glioblastoma." Cell 155 (2):462-77. doi: 10.1016/j.cell.2013.09.034.

Bruno, I. G., W. Jin, and G. J. Cote. 2004. "Correction of aberrant FGFR1 alternative RNA splicing through targeting of intronic regulatory elements." Hum Mol Genet 13 (20):2409-20. doi: 10.1093/hmg/ddh272.

Caldas, H., Y. Jiang, M. P. Holloway, J. Fangusaro, C. Mahotka, E. M. Conway, and R. A. Altura. 2005. "Survivin splice variants regulate the balance between proliferation and cell death." Oncogene 24 (12):1994-2007. doi: 10.1038/sj.onc.1208350.

Camacho-Vanegas, O., G. Narla, M. S. Teixeira, A. DiFeo, A. Misra, G. Singh, A. M. Chan, S. L. Friedman, B. G. Feuerstein, and J. A. Martignetti. 2007. "Functional inactivation of the KLF6 tumor suppressor gene by loss of heterozygosity and increased alternative splicing in glioblastoma." Int J Cancer 121 (6):1390-5. doi: 10.1002/ijc.22809.

Campos, B., F. Wan, M. Farhadi, A. Ernst, F. Zeppernick, K. E. Tagscherer, R. Ahmadi, J. Lohr, C. Dictus, G. Gdynia, S. E. Combs, V. Goidts, B. M. Helmke, V. Eckstein, W. Roth, P. Beckhove, P. Lichter, A. Unterberg, B. Radlwimmer, and C. Herold-Mende. 2010. "Differentiation therapy exerts antitumor effects on stem-like glioma cells." Clin Cancer Res 16 (10):2715-28. doi: 10.1158/1078-0432.CCR-09-1800.

Carnemolla, B., P. Castellani, M. Ponassi, L. Borsi, S. Urbini, G. Nicolo, A. Dorcaratto, G. Viale, G. Winter, D. Neri, and L. Zardi. 1999. "Identification of a glioblastoma- associated tenascin-C isoform by a high affinity recombinant antibody." Am J Pathol 154 (5):1345-52. doi: 10.1016/S0002-9440(10)65388-6.

Carpenter, R. L., and H. W. Lo. 2012. "Hedgehog pathway and GLI1 isoforms in human cancer." Discov Med 13 (69):105-13.

Chan, A. M., J. S. Rubin, D. P. Bottaro, D. W. Hirschfield, M. Chedid, and S. A. Aaronson. 1991. "Identification of a competitive HGF antagonist encoded by an alternative transcript." Science 254 (5036):1382-5.

Chaneton, B., and E. Gottlieb. 2012. "Rocking cell metabolism: revised functions of the key glycolytic regulator PKM2 in cancer." Trends Biochem Sci 37 (8):309-16. doi: 10.1016/j.tibs.2012.04.003.

Chen, C. H., S. L. Howng, T. S. Cheng, M. H. Chou, C. Y. Huang, and Y. R. Hong. 2003. "Molecular characterization of human ninein protein: two distinct subdomains required for centrosomal targeting and regulating signals in cell cycle." Biochem Biophys Res Commun 308 (4):975-83.

Chen, C. H., S. L. Howng, S. L. Hwang, C. K. Chou, C. H. Liao, and Y. R. Hong. 2000. "Differential expression of four human dynamin-like protein variants in brain tumors." DNA Cell Biol 19 (3):189-94. doi: 10.1089/104454900314573.

Chen, W. S., C. S. Lazar, K. A. Lund, J. B. Welsh, C. P. Chang, G. M. Walton, C. J. Der, H. S. Wiley, G. N. Gill, and M. G. Rosenfeld. 1989. "Functional independence of the epidermal growth factor receptor from a domain required for ligand-induced internalization and calcium regulation." Cell 59 (1):33-43.

Chen, X., L. Zhang, I. Y. Zhang, J. Liang, H. Wang, M. Ouyang, S. Wu, A. Carvalho da Fonseca, L. Weng, Y. Yamamoto, H. Yamamoto, R. Natarajan, and B. Badie. 2014. "RAGE Expression in Tumor-associated Macrophages Promotes Angiogenesis in Glioma." Cancer Res. doi: 10.1158/0008-5472.CAN-14-1240.

Cheng, S. Y., M. Nagane, H. S. Huang, and W. K. Cavenee. 1997. "Intracerebral tumor- associated hemorrhage caused by overexpression of the vascular endothelial growth factor isoforms VEGF121 and VEGF165 but not VEGF189." Proc Natl Acad Sci U S A 94 (22):12081-7.

Cheung, H. C., L. J. Corley, G. N. Fuller, I. E. McCutcheon, and G. J. Cote. 2006. "Polypyrimidine tract binding protein and Notch1 are independently re-expressed in glioma." Mod Pathol 19 (8):1034-41. doi: 10.1038/modpathol.3800635.

Cheung, H. C., T. Hai, W. Zhu, K. A. Baggerly, S. Tsavachidis, R. Krahe, and G. J. Cote. 2009. "Splicing factors PTBP1 and PTBP2 promote proliferation and migration of glioma cell lines." Brain 132 (Pt 8):2277-88. doi: 10.1093/brain/awp153.

Cho, J., S. Pastorino, Q. Zeng, X. Xu, W. Johnson, S. Vandenberg, R. Verhaak, A. D. Cherniack, H. Watanabe, A. Dutt, J. Kwon, Y. S. Chao, R. C. Onofrio, D. Chiang, Y. Yuza, S. Kesari, and M. Meyerson. 2011. "Glioblastoma-derived epidermal growth factor receptor carboxyl-terminal deletion mutants are transforming and are sensitive to EGFR-directed therapies." Cancer Res 71 (24):7587-96. doi: 10.1158/0008-5472.CAN-11-0821.

Christofk, H. R., M. G. Vander Heiden, M. H. Harris, A. Ramanathan, R. E. Gerszten, R. Wei, M. D. Fleming, S. L. Schreiber, and L. C. Cantley. 2008. "The M2 splice isoform of pyruvate kinase is important for cancer metabolism and tumour growth." Nature 452 (7184):230-3. doi: 10.1038/nature06734.

Chunduru, S., H. Kawami, R. Gullick, W. J. Monacci, G. Dougherty, and M. L. Cutler. 2002. "Identification of an alternatively spliced RNA for the Ras suppressor RSU-1 in human gliomas." J Neurooncol 60 (3):201-11.

Clower, C. V., D. Chatterjee, Z. Wang, L. C. Cantley, M. G. Vander Heiden, and A. R. Krainer. 2010. "The alternative splicing repressors hnRNP A1/A2 and PTB influence pyruvate kinase isoform expression and cell metabolism." Proc Natl Acad Sci U S A 107 (5):1894-9. doi: 10.1073/pnas.0914845107.

Cui, D., Q. Xu, K. Wang, and X. Che. 2010. "Gli1 is a potential target for alleviating multidrug resistance of gliomas." J Neurol Sci 288 (1-2):156-66. doi: 10.1016/j.jns.2009.09.006.

David, C. J., and J. L. Manley. 2010. "Alternative pre-mRNA splicing regulation in cancer: pathways and programs unhinged." Genes Dev 24 (21):2343-64. doi: 10.1101/gad.1973010. 
Decker, S. J., C. Alexander, and T. Habib. 1992. "Epidermal growth factor (EGF)-stimulated tyrosine phosphorylation and EGF receptor degradation in cells expressing EGF receptors truncated at residue 973." J Biol Chem 267 (2):1104-8.

Dours-Zimmermann, M. T., and D. R. Zimmermann. 1994. "A novel glycosaminoglycan attachment domain identified in two alternative splice variants of human versican." J Biol Chem 269 (52):32992-8.

Faustino, N. A., and T. A. Cooper. 2003. "Pre-mRNA splicing and human disease." Genes Dev 17 (4):419-37. doi: 10.1101/gad.1048803.

Feller, S. M., G. Posern, J. Voss, C. Kardinal, D. Sakkab, J. Zheng, and B. S. Knudsen. 1998. "Physiological signals and oncogenesis mediated through Crk family adapter proteins." J Cell Physiol 177 (4):535-52. doi: 10.1002/(SICI)1097-4652(199812)177:4<535::AID- JCP5>3.0.CO;2-E.

Feng, H., B. Hu, K. Vuori, J. N. Sarkaria, F. B. Furnari, W. K. Cavenee, and S. Y. Cheng. 2014. "EGFRvIII stimulates glioma growth and invasion through PKAdependent serine phosphorylation of Dock180." Oncogene 33 (19):2504-12. doi: 10.1038/onc.2013.198.

Ferrarese, R., G. R. th Harsh, A. K. Yadav, E. Bug, D. Maticzka, W. Reichardt, S. M. Dombrowski, T. E. Miller, A. P. Masilamani, F. Dai, H. Kim, M. Hadler, D. M. Scholtens, I. L. Yu, J. Beck, V. Srinivasasainagendra, F. Costa, N. Baxan, D. Pfeifer, D. von Elverfeldt, R. Backofen, A. Weyerbrock, C. W. Duarte, X. He, M. Prinz, J. P. Chandler, H. Vogel, A. Chakravarti, J. N. Rich, M. S. Carro, and M. Bredel. 2014. "Lineage-specific splicing of a brain-enriched alternative exon promotes glioblastoma progression." J Clin Invest 124 (7):2861-76. doi: 10.1172/JCI68836.

Floor, S. L., J. E. Dumont, C. Maenhaut, and E. Raspe. 2012. "Hallmarks of cancer: of all cancer cells, all the time?" Trends Mol Med 18 (9):509-15. doi: 10.1016/j.molmed.2012.06.005.

Francis, J. M., C. Z. Zhang, C. L. Maire, J. Jung, V. E. Manzo, V. A. Adalsteinsson, H. Homer, S. Haidar, B. Blumenstiel, C. S. Pedamallu, A. H. Ligon, J. C. Love, M. Meyerson, and K. L. Ligon. 2014. "EGFR variant heterogeneity in glioblastoma resolved through single- nucleus sequencing." Cancer Discov 4 (8):956-71. doi: 10.1158/2159-8290.CD-13-0879.

Frederick, L., X. Y. Wang, G. Eley, and C. D. James. 2000. "Diversity and frequency of epidermal growth factor receptor mutations in human glioblastomas." Cancer Res 60 (5):1383-7.

Fu, R. H., S. P. Liu, S. J. Huang, H. J. Chen, P. R. Chen, Y. H. Lin, Y. C. Ho, W. L. Chang, C. H. Tsai, W. C. Shyu, and S. Z. Lin. 2013. "Aberrant alternative splicing events in Parkinson's disease." Cell Transplant 22 (4):653-61. doi: 10.3727/096368912X655154.

Glatz, D. C., D. Rujescu, Y. Tang, F. J. Berendt, A. M. Hartmann, F. Faltraco, C. Rosenberg, C. Hulette, K. Jellinger, H. Hampel, P. Riederer, H. J. Moller, A. Andreadis, K. Henkel, and S. Stamm. 2006. "The alternative splicing of tau exon 10 and its regulatory proteins CLK2 and TRA2-BETA1 changes in sporadic Alzheimer's disease." J Neurochem 96 (3):635-44. doi: 10.1111/j.1471-4159.2005.03552.x.

Golan-Gerstl, R., M. Cohen, A. Shilo, S. S. Suh, A. Bakacs, L. Coppola, and R. Karni. 2011. "Splicing factor hnRNP A2/B1 regulates tumor suppressor gene splicing and is an oncogenic driver in glioblastoma." Cancer Res 71 (13):4464-72. doi: 10.1158/0008-5472.CAN-10-4410.

Guerin, C., C. Luddy, R. Abounader, B. Lal, and J. Laterra. 2000. "Glioma inhibition by HGF/NK2, an antagonist of scatter factor/hepatocyte growth factor." Biochem Biophys Res Commun 273 (1):287-93. doi: 10.1006/bbrc.2000.2935.

Guillaudeau, A., K. Durand, B. Bessette, A. Chaunavel, I. Pommepuy, F. Projetti, S. Robert, F. Caire, H. Rabinovitch-Chable, and F. Labrousse. 2012. "EGFR soluble isoforms and their transcripts are expressed in meningiomas." PLoS One 7 (5):e37204. doi: 10.1371/journal.pone.0037204.

Guillaudeau, A., K. Durand, H. Rabinovitch-Chable, I. Pommepuy, L. Mesturoux, S. Robert, A. Chaunavel, J. J. Moreau, and F. Labrousse. 2012. "Adult diffuse gliomas produce mRNA transcripts encoding EGFR isoforms lacking a tyrosine kinase domain." Int J Oncol 40 (4):1142-52. doi: 10.3892/ijo.2011.1287.

Hamasuna, R., H. Kataoka, T. Moriyama, H. Itoh, M. Seiki, and M. Koono. 1999. "Regulation of matrix metalloproteinase-2 (MMP-2) by hepatocyte growth factor/scatter factor (HGF/SF) in human glioma cells: HGF/SF enhances MMP-2 expression and activation accompanying up-regulation of membrane type1 MMP." Int J Cancer 82 (2):274-81.

Hamid, F. M., and E. V. Makeyev. 2014. "Regulation of mRNA abundance by polypyrimidine tract-binding protein-controlled alternate 5' splice site choice." PLoS Genet 10 (11):e1004771. doi: 10.1371/journal.pgen.1004771.

Han, A., P. Stoilov, A. J. Linares, Y. Zhou, X. D. Fu, and D. L. Black. 2014. "De novo prediction of PTBP1 binding and splicing targets reveals unexpected features of its RNA recognition and function." PLoS Comput Biol 10 (1):e1003442. doi: 10.1371/journal.pcbi.1003442.

Hanahan, D., and R. A. Weinberg. 2000. "The hallmarks of cancer." Cell 100 (1):57-70.

Hanahan, D., and R. A. Weinberg. 2011. "Hallmarks of cancer: the next generation." Cell 144 (5):646-74. doi: 10.1016/j.cell.2011.02.013.

Hannon, G. J., D. Casso, and D. Beach. 1994. "KAP: a dual specificity phosphatase that interacts with cyclin-dependent kinases." Proc Natl Acad Sci U S A 91 (5):1731-5

Hong, X., F. Jiang, S. N. Kalkanis, Z. G. Zhang, X. Zhang, X. Zheng, H. Jiang, T. Mikkelsen, and M. Chopp. 2008. "Increased chemotactic migration and growth in heparanase- overexpressing human U251n glioma cells." J Exp Clin Cancer Res 27:23. doi: 10.1186/1756-9966-27-23.

Hong, X., K. K. Nelson, A. C. deCarvalho, and S. N. Kalkanis. 2010. "Heparanase expression of glioma in human and animal models." J Neurosurg 113 (2):261-9. doi: 10.3171/2009.9.JNS09682.

Hu, J., A. L. Ho, L. Yuan, B. Hu, S. Hua, S. S. Hwang, J. Zhang, T. Hu, H. Zheng, B. Gan, G. Wu, Y. A. Wang, L. Chin, and R. A. DePinho. 2013. "From the Cover: Neutralization of terminal differentiation in gliomagenesis." Proc Natl Acad Sci U S A 110 (36):14520-7. doi: 10.1073/pnas.1308610110.

Huang, H., J. Held-Feindt, R. Buhl, H. M. Mehdorn, and R. Mentlein. 2005. "Expression of VEGF and its receptors in different brain tumors." Neurol Res 27 (4):3717. doi: 10.1179/016164105X39833.

Huang, H. S., M. Nagane, C. K. Klingbeil, H. Lin, R. Nishikawa, X. D. Ji, C. M. Huang, G. N. Gill, H. S. Wiley, and W. K. Cavenee. 1997. "The enhanced tumorigenic activity of a mutant epidermal growth factor receptor common in human cancers is mediated by threshold levels of constitutive tyrosine phosphorylation and unattenuated signaling." J Biol Chem 272 (5):2927-35.

Huang, Y., X. Chen, N. Chen, L. Nie, M. Xu, and Q. Zhou. 2011. "Expression and prognostic significance of survivin splice variants in diffusely infiltrating astrocytoma." J Clin Pathol 64 (11):953-9. doi: 10.1136/jclinpath-2011-200066.

Hudson, B. I., A. M. Carter, E. Harja, A. Z. Kalea, M. Arriero, H. Yang, P. J. Grant, and A. M. Schmidt. 2008. "Identification, classification, and expression of RAGE gene splice variants." FASEB J 22 (5):1572-80. doi: 10.1096/fj.07-9909com.

Humphrey, P. A., L. M. Gangarosa, A. J. Wong, G. E. Archer, M. Lund-Johansen, R. Bjerkvig, O. D. Laerum, H. S. Friedman, and D. D. Bigner. 1991. "Deletionmutant epidermal growth factor receptor in human gliomas: effects of type II mutation on receptor function." Biochem Biophys Res Commun 178 (3):141320.

Humphrey, P. A., A. J. Wong, B. Vogelstein, H. S. Friedman, M. H. Werner, D. D. Bigner, and S. H. Bigner. 1988. "Amplification and expression of the epidermal growth factor receptor gene in human glioma xenografts." Cancer Res 48 (8):2231-8.

Inda, M. M., R. Bonavia, A. Mukasa, Y. Narita, D. W. Sah, S. Vandenberg, C. Brennan, T. G. Johns, R. Bachoo, P. Hadwiger, P. Tan, R. A. Depinho, W. Cavenee, and F. Furnari.2010. "Tumor heterogeneity is an active process maintained by a mutant EGFR-induced cytokine circuit in glioblastoma." Genes Dev 24 (16):1731-45. doi: 10.1101/gad.1890510.

Izaguirre, D. I., W. Zhu, T. Hai, H. C. Cheung, R. Krahe, and G. J. Cote. 2012. "PTBP1- dependent regulation of USP5 alternative RNA splicing plays a role in glioblastoma tumorigenesis." Mol Carcinog 51 (11):895-906. doi: 10.1002/mc.20859. 
Jin, W., I. G. Bruno, T. X. Xie, L. J. Sanger, and G. J. Cote. 2003. "Polypyrimidine tract-binding protein down-regulates fibroblast growth factor receptor 1 alpha-exon inclusion." Cancer Res 63 (19):6154-7.

Jin, W., E. S. Huang, W. Bi, and G. J. Cote. 1998. "Exon sequence is required for regulated RNA splicing of the human fibroblast growth factor receptor-1 alphaexon." J Biol Chem 273 (26):16170-6.

Jin, W., E. S. Huang, W. Bi, and G. J. Cote. 1999. "Redundant intronic repressors function to inhibit fibroblast growth factor receptor-1 alpha-exon recognition in glioblastoma cells." J Biol Chem 274 (39):28035-41.

Jin, W., I. E. McCutcheon, G. N. Fuller, E. S. Huang, and G. J. Cote. 2000. "Fibroblast growth factor receptor-1 alpha-exon exclusion and polypyrimidine tract-binding protein in glioblastoma multiforme tumors." Cancer Res 60 (5):1221-4.

Jules, J., D. Maiguel, and B. I. Hudson. 2013. "Alternative splicing of the RAGE cytoplasmic domain regulates cell signaling and function." PLoS One 8 (11):e78267. doi: 10.1371/journal.pone.0078267.

Jurica, M. S., A. Mesecar, P. J. Heath, W. Shi, T. Nowak, and B. L. Stoddard. 1998. "The allosteric regulation of pyruvate kinase by fructose-1,6-bisphosphate." Structure 6 (2):195-210

Karni, R., E. de Stanchina, S. W. Lowe, R. Sinha, D. Mu, and A. R. Krainer. 2007. "The gene encoding the splicing factor SF2/ASF is a proto-oncogene." Nat Struct Mol Biol 14 (3):185-93. doi: 10.1038/nsmb1209.

Kastenhuber, E. R., J. T. Huse, S. H. Berman, A. Pedraza, J. Zhang, Y. Suehara, A. Viale, M. Cavatore, A. Heguy, N. Szerlip, M. Ladanyi, and C. W. Brennan. 2014. "Quantitative assessment of intragenic receptor tyrosine kinase deletions in primary glioblastomas: their prevalence and molecular correlates." Acta Neuropathol 127 (5):747-59. doi: 10.1007/s00401-013-1217-3.

Kikuchi, Y., T. Kakeya, O. Nakajima, A. Sakai, K. Ikeda, N. Yamaguchi, T. Yamazaki, K. Tanamoto, H. Matsuda, J. Sawada, and K. Takatori. 2008. "Hypoxia induces expression of a GPI-anchorless splice variant of the prion protein." FEBS J 275 (11):2965-76. doi: 10.1111/j.1742-4658.2008.06452.x.

Kim, E., A. Goren, and G. Ast. 2008. "Alternative splicing: current perspectives." Bioessays 30 (1):38-47. doi: 10.1002/bies.20692.

Kinzler, K. W., S. H. Bigner, D. D. Bigner, J. M. Trent, M. L. Law, S. J. O'Brien, A. J. Wong, and B. Vogelstein. 1987. "Identification of an amplified, highly expressed gene in a human glioma." Science 236 (4797):70-3.

Kraus, A., F. Neff, M. Behn, M. Schuermann, K. Muenkel, and J. Schlegel. 1999. "Expression of alternatively spliced mdm2 transcripts correlates with stabilized wildtype p53 protein in human glioblastoma cells." Int J Cancer 80 (6):930-4.

Kuan, C. T., C. J. Wikstrand, and D. D. Bigner. 2001. "EGF mutant receptor vIII as a molecular target in cancer therapy." Endocr Relat Cancer 8 (2):83-96.

Lamszus, K., N. O. Schmidt, L. Jin, J. Laterra, D. Zagzag, D. Way, M. Witte, M. Weinand, I. D. Goldberg, M. Westphal, and E. M. Rosen. 1998. "Scatter factor promotes motility of human glioma and neuromicrovascular endothelial cells." Int J Cancer 75 (1):19-28.

Laterra, J., M. Nam, E. Rosen, J. S. Rao, K. Lamszus, I. D. Goldberg, and P. Johnston. 1997. "Scatter factor/hepatocyte growth factor gene transfer enhances glioma growth and angiogenesis in vivo." Lab Invest 76 (4):565-77.

Latour, I., D. F. Louw, A. M. Beedle, J. Hamid, G. R. Sutherland, and G. W. Zamponi. 2004. "Expression of T-type calcium channel splice variants in human glioma." Glia 48 (2):112-9. doi: 10.1002/glia.20063.

Lefave, C. V., M. Squatrito, S. Vorlova, G. L. Rocco, C. W. Brennan, E. C. Holland, Y. X. Pan, and L. Cartegni. 2011. "Splicing factor hnRNPH drives an oncogenic splicing switch in gliomas." EMBO J 30 (19):4084-97. doi: 10.1038/emboj.2011.259.

Li, Z., P. Yang, and Z. Li. 2014. "The multifaceted regulation and functions of PKM2 in tumor progression." Biochim Biophys Acta 1846 (2):285-296. doi: 10.1016/j.bbcan.2014.07.008.

Lo, H. W., H. Zhu, X. Cao, A. Aldrich, and F. Ali-Osman. 2009. "A novel splice variant of GLI1 that promotes glioblastoma cell migration and invasion." Cancer Res 69 (17):6790-8. doi: 10.1158/0008-5472.CAN-09-0886.

Loilome, W., A. D. Joshi, C. M. ap Rhys, S. Piccirillo, A. L. Vescovi, G. L. Gallia, and G. J. Riggins. 2009. "Glioblastoma cell growth is suppressed by disruption of Fibroblast Growth Factor pathway signaling." J Neurooncol 94 (3):359-66. doi: 10.1007/s11060-009-9885-5.

Louis, D. N., H. Ohgaki, O. D. Wiestler, W. K. Cavenee, P. C. Burger, A. Jouvet, B. W. Scheithauer, and P. Kleihues. 2007. of the central nervous system." Acta Neuropathol 114 (2):97-109. doi: 10.1007/s00401-007-0243-4.

Lu, K. V., S. Zhu, A. Cvrljevic, T. T. Huang, S. Sarkaria, D. Ahkavan, J. Dang, E. B. Dinca, S. B. Plaisier, I. Oderberg, Y. Lee, Z. Chen, J. S. Caldwell, Y. Xie, J. A. Loo, D. Seligson, A. Chakravari, F. Y. Lee, R. Weinmann, T. F. Cloughesy, S. F. Nelson, G. Bergers, T. Graeber, F. B. Furnari, C. D. James, W. K. Cavenee, T. G. Johns, and P. S. Mischel. 2009. "Fyn and SRC are effectors of oncogenic epidermal growth factor receptor signaling in glioblastoma patients." Cancer Res 69 (17):6889-98. doi: 10.1158/0008-5472.CAN-09-0347.

Luwor, R. B., T. G. Johns, C. Murone, H. J. Huang, W. K. Cavenee, G. Ritter, L. J. Old, A. W. Burgess, and A. M. Scott. 2001. "Monoclonal antibody 806 inhibits the growth of tumor xenografts expressing either the de2-7 or amplified epidermal growth factor receptor (EGFR) but not wild-type EGFR." Cancer Res 61 (14):5355-61.

Matera, A. G., and Z. Wang. 2014. "A day in the life of the spliceosome." Nat Rev Mol Cell Biol 15 (2):108-21. doi: 10.1038/nrm3742.

Matsumoto, R., M. Tada, M. Nozaki, C. L. Zhang, Y. Sawamura, and H. Abe. 1998. "Short alternative splice transcripts of the mdm2 oncogene correlate to malignancy in human astrocytic neoplasms." Cancer Res 58 (4):609-13.

Matsushita, H., A. Uenaka, T. Ono, K. Hasegawa, S. Sato, F. Koizumi, K. Nakagawa, M. Toda, T. Shingo, T. Ichikawa, Y. Noguchi, T. Tamiya, T. Furuta, T. Kawase, I. Date, and E. Nakayama. 2005. "Identification of glioma-specific RFX4-E and -F isoforms and humoral immune response in patients." Cancer Sci 96 (11):801-9. doi: 10.1111/j.1349-7006.2005.00112.x.

Mishima, K., T. G. Johns, R. B. Luwor, A. M. Scott, E. Stockert, A. A. Jungbluth, X. D. Ji, P. Suvarna, J. R. Voland, L. J. Old, H. J. Huang, and W. K. Cavenee. 2001. "Growth suppression of intracranial xenografted glioblastomas overexpressing mutant epidermal growth factor receptors by systemic administration of monoclonal antibody (mAb) 806, a novel monoclonal antibody directed to the receptor." Cancer Res 61 (14):5349-54.

Moriyama, T., H. Kataoka, R. Hamasuna, K. Yokogami, H. Uehara, H. Kawano, T. Goya, H. Tsubouchi, M. Koono, and S. Wakisaka. 1998. "Up-regulation of vascular endothelial growth factor induced by hepatocyte growth factor/scatter factor stimulation in human glioma cells." Biochem Biophys Res Commun 249 (1):737. doi: 10.1006/bbrc.1998.9078.

Mulherkar, N., K. V. Prasad, and B. S. Prabhakar. 2007. "MADD/DENN splice variant of the IG20 gene is a negative regulator of caspase-8 activation. Knockdown enhances TRAIL- induced apoptosis of cancer cells." J Biol Chem 282 (16):11715-21. doi: 10.1074/jbc.M701085200.

Nagane, M., F. Coufal, H. Lin, O. Bogler, W. K. Cavenee, and H. J. Huang. 1996. "A common mutant epidermal growth factor receptor confers enhanced tumorigenicity on human glioblastoma cells by increasing proliferation and reducing apoptosis." Cancer Res 56 (21):5079-86.

Nagane, M., A. Levitzki, A. Gazit, W. K. Cavenee, and H. J. Huang. 1998. "Drug resistance of human glioblastoma cells conferred by a tumor-specific mutant epidermal growth factor receptor through modulation of Bcl-XL and caspase-3-like proteases." Proc Natl Acad Sci U S A 95 (10):5724-9.

Nagane, M., Y. Narita, K. Mishima, A. Levitzki, A. W. Burgess, W. K. Cavenee, and H. J. Huang. 2001. "Human glioblastoma xenografts overexpressing a tumorspecific mutant epidermal growth factor receptor sensitized to cisplatin by the AG1478 tyrosine kinase inhibitor." J Neurosurg 95 (3):472-9. doi: 10.3171/jns.2001.95.3.0472 
Narla, G., A. Difeo, H. L. Reeves, D. J. Schaid, J. Hirshfeld, E. Hod, A. Katz, W. B. Isaacs, S. Hebbring, A. Komiya, S. K. McDonnell, K. E. Wiley, S. J. Jacobsen, S. D. Isaacs, P. C. Walsh, S. L. Zheng, B. L. Chang, D. M. Friedrichsen, J. L. Stanford, E. A. Ostrander, A. M. Chinnaiyan, M. A. Rubin, J. Xu, S. N. Thibodeau, S. L. Friedman, and J. A. Martignetti. 2005. "A germline DNA polymorphism enhances alternative splicing of the KLF6 tumor suppressor gene and is associated with increased prostate cancer risk." Cancer Res 65 (4):1213-22. doi: 10.1158/0008-5472.CAN-04-4249.

Narla, G., A. DiFeo, S. Yao, A. Banno, E. Hod, H. L. Reeves, R. F. Qiao, O. Camacho-Vanegas, A. Levine, A. Kirschenbaum, A. M. Chan, S. L. Friedman, and J. A. Martignetti. 2005. "Targeted inhibition of the KLF6 splice variant, KLF6 SV1, suppresses prostate cancer cell growth and spread." Cancer Res 65 (13):5761-8. doi: 10.1158/0008-5472.CAN-05-0217.

Nasser, N. J., A. Avivi, I. Shafat, E. Edovitsky, E. Zcharia, N. Ilan, I. Vlodavsky, and E. Nevo. 2009. "Alternatively spliced Spalax heparanase inhibits extracellular matrix degradation, tumor growth, and metastasis." Proc Natl Acad Sci U S A 106 (7):2253-8. doi: 10.1073/pnas.0812846106.

Nathanson, D. A., B. Gini, J. Mottahedeh, K. Visnyei, T. Koga, G. Gomez, A. Eskin, K. Hwang, J. Wang, K. Masui, A. Paucar, H. Yang, M. Ohashi, S. Zhu, J. Wykosky, R. Reed, S. F. Nelson, T. F. Cloughesy, C. D. James, P. N. Rao, H. I. Kornblum, J. R. Heath, W. K. Cavenee, F. B. Furnari, and P. S. Mischel. 2014. "Targeted therapy resistance mediated by dynamic regulation of extrachromosomal mutant EGFR DNA." Science 343 (6166):72-6. doi: $10.1126 /$ science. 1241328

Nicholas, M. K., R. V. Lukas, N. F. Jafri, L. Faoro, and R. Salgia. 2006. "Epidermal growth factor receptor - mediated signal transduction in the development and therapy of gliomas." Clin Cancer Res 12 (24):7261-70. doi: 10.1158/1078-0432.CCR-06-0874.

Nilsen, T. W. 2003. "The spliceosome: the most complex macromolecular machine in the cell?" Bioessays 25 (12):1147-9. doi: 10.1002/bies.10394

Nishikawa, R., X. D. Ji, R. C. Harmon, C. S. Lazar, G. N. Gill, W. K. Cavenee, and H. J. Huang. 1994. "A mutant epidermal growth factor receptor common in human glioma confers enhanced tumorigenicity." Proc Natl Acad Sci U S A 91 (16):7727-31.

Ogiso, H., R. Ishitani, O. Nureki, S. Fukai, M. Yamanaka, J. H. Kim, K. Saito, A. Sakamoto, M. Inoue, M. Shirouzu, and S. Yokoyama. 2002. "Crystal structure of the complex of human epidermal growth factor and receptor extracellular domains." Cell 110 (6):775-87.

Okamoto, I., L. C. Kenyon, D. R. Emlet, T. Mori, J. Sasaki, S. Hirosako, Y. Ichikawa, H. Kishi, A. K. Godwin, M. Yoshioka, M. Suga, M. Matsumoto, and A. J. Wong. 2003. "Expression of constitutively activated EGFRvIII in non-small cell lung cancer." Cancer Sci 94 (1):50-6.

Oltean, S., and D. O. Bates. 2014. "Hallmarks of alternative splicing in cancer." Oncogene 33 (46):5311-5318. doi: 10.1038/onc.2013.533.

Park, I. H., S. I. Yeon, J. H. Youn, J. E. Choi, N. Sasaki, I. H. Choi, and J. S. Shin. 2004. "Expression of a novel secreted splice variant of the receptor for advanced glycation end products (RAGE) in human brain astrocytes and peripheral blood mononuclear cells." Mol Immunol 40 (16):1203-11.

Pedersen, M. W., M. Meltorn, L. Damstrup, and H. S. Poulsen. 2001. "The type III epidermal growth factor receptor mutation. Biological significance and potential target for anti- cancer therapy." Ann Oncol 12 (6):745-60.

Perez-Torres, M., B. L. Valle, N. J. Maihle, L. Negron-Vega, R. Nieves-Alicea, and E. M. Cora. 2008. "Shedding of epidermal growth factor receptor is a regulated process that occurs with overexpression in malignant cells." Exp Cell Res 314 (16):2907-18. doi: 10.1016/j.yexcr.2008.07.013.

Piccione, E. C., T. J. Lieu, C. F. Gentile, T. R. Williams, A. J. Connolly, A. K. Godwin, A. C. Koong, and A. J. Wong. 2012. "A novel epidermal growth factor receptor variant lacking multiple domains directly activates transcription and is overexpressed in tumors." Oncogene 31 (24):2953-67. doi: 10.1038/onc.2011.465.

Pines, G., P. H. Huang, Y. Zwang, F. M. White, and Y. Yarden. 2010. "EGFRvIV: a previously uncharacterized oncogenic mutant reveals a kinase autoinhibitory mechanism." Oncogene 29 (43):5850-60. doi: 10.1038/onc.2010.313.

Puthalakath, H., D. C. Huang, L. A. O'Reilly, S. M. King, and A. Strasser. 1999. "The proapoptotic activity of the Bcl-2 family member Bim is regulated by interaction with the dynein motor complex." Mol Cell 3 (3):287-96.

Reardon, D. A., G. Akabani, R. E. Coleman, A. H. Friedman, H. S. Friedman, J. E. Herndon, 2nd, I. Cokgor, R. E. McLendon, C. N. Pegram, J. M. Provenzale, J. A. Quinn, J. N. Rich, L. V. Regalado, J. H. Sampson, T. D. Shafman, C. J. Wikstrand, T. Z. Wong, X. G. Zhao, M. R. Zalutsky, and D. D. Bigner. 2002. "Phase II trial of murine (131)I-labeled antitenascin monoclonal antibody 81C6 administered into surgically created resection cavities of patients with newly diagnosed malignant gliomas." J Clin Oncol 20 (5):1389-97.

Reiter, J. L., and N. J. Maihle. 1996. "A $1.8 \mathrm{~kb}$ alternative transcript from the human epidermal growth factor receptor gene encodes a truncated form of the receptor." Nucleic Acids Res 24 (20):4050-6.

Reiter, J. L., D. W. Threadgill, G. D. Eley, K. E. Strunk, A. J. Danielsen, C. S. Sinclair, R. S. Pearsall, P. J. Green, D. Yee, A. L. Lampland, S. Balasubramaniam, T. D. Crossley, T. R. Magnuson, C. D. James, and N. J. Maihle. 2001. "Comparative genomic sequence analysis and isolation of human and mouse alternative EGFR transcripts encoding truncated receptor isoforms." Genomics 71 (1):1-20. doi: 10.1006/geno.2000.6341.

Sadeque, A., N. V. Serao, B. R. Southey, K. R. Delfino, and S. L. Rodriguez-Zas. 2012. "Identification and characterization of alternative exon usage linked glioblastoma multiforme survival." BMC Med Genomics 5:59. doi: 10.1186/1755-8794-5-59.

Schwechheimer, K., S. Huang, and W. K. Cavenee. 1995. "EGFR gene amplification-- rearrangement in human glioblastomas." Int J Cancer 62 (2):145-8.

Scott, A. M., F. T. Lee, N. Tebbutt, R. Herbertson, S. S. Gill, Z. Liu, E. Skrinos, C. Murone, T. H. Saunder, B. Chappell, A. T. Papenfuss, A. M. Poon, W. Hopkins, F. E. Smyth, D. MacGregor, L. M. Cher, A. A. Jungbluth, G. Ritter, M. W. Brechbiel, R. Murphy, A. W. Burgess, E. W. Hoffman, T. G. Johns, and L. J. Old 2007. "A phase I clinical trial with monoclonal antibody ch806 targeting transitional state and mutant epidermal growth factor receptors." Proc Natl Acad Sci U S A 104 (10):4071-6. doi: 10.1073/pnas.0611693104.

Shimokawa, T., U. Tostar, M. Lauth, R. Palaniswamy, M. Kasper, R. Toftgard, and P. G. Zaphiropoulos. 2008. "Novel human glioma-associated oncogene 1 (GLI1) splice variants reveal distinct mechanisms in the terminal transduction of the hedgehog signal." J Biol Chem 283 (21):14345-54. doi: 10.1074/jbc.M800299200.

Simon, P., M. Schneck, T. Hochstetter, E. Koutsouki, M. Mittelbronn, A. Merseburger, C. Weigert, A. Niess, and F. Lang. 2007. "Differential regulation of serum- and glucocorticoid-inducible kinase 1 (SGK1) splice variants based on alternative initiation of transcription." Cell Physiol Biochem 20 (6):715-28. doi: $10.1159 / 000110432$

Smith, D. J., C. C. Query, and M. M. Konarska. 2008. "Nought may endure but mutability": spliceosome dynamics and the regulation of splicing." Mol Cell 30 (6):657-66. doi: 10.1016/j.molcel.2008.04.013.

Song, S. W., G. N. Fuller, H. Zheng, and W. Zhang. 2005. "Inactivation of the invasion inhibitory gene IIp45 by alternative splicing in gliomas." Cancer Res 65 (9):3562-7. doi: 10.1158/0008-5472.CAN-04-3392

Srinivasula, S. M., M. Ahmad, Y. Guo, Y. Zhan, Y. Lazebnik, T. Fernandes-Alnemri, and E. S. Alnemri. 1999. "Identification of an endogenous dominant-negative short isoform of caspase-9 that can regulate apoptosis." Cancer Res 59 (5):999-1002.

Stupp, R., W. P. Mason, M. J. van den Bent, M. Weller, B. Fisher, M. J. Taphoorn, K. Belanger, A. A. Brandes, C. Marosi, U. Bogdahn, J. Curschmann, R. C. Janzer, S. K. Ludwin, T. Gorlia, A. Allgeier, D. Lacombe, J. G. Cairncross, E. Eisenhauer, R. O. Mirimanoff, Research European Organisation for, Tumor Treatment of Cancer Brain, Groups Radiotherapy, and Group National Cancer Institute of Canada Clinical Trials. 2005. "Radiotherapy plus concomitant and adjuvant temozolomide for glioblastoma." N Engl J Med 352 (10):987-96. doi: 10.1056/NEJMoa043330.

Sugawa, N., A. J. Ekstrand, C. D. James, and V. P. Collins. 1990. "Identical splicing of aberrant epidermal growth factor receptor transcripts from amplified rearranged genes in human glioblastomas." Proc Natl Acad Sci U S A 87 (21):8602-6. 
Suzuki, S. O., R. Kitai, J. Llena, S. C. Lee, J. E. Goldman, and B. Shafit-Zagardo. 2002. "MAP-2e, a novel MAP-2 isoform, is expressed in gliomas and delineates tumor architecture and patterns of infiltration." J Neuropathol Exp Neurol 61 (5):403-12.

Tafani, M., M. Di Vito, A. Frati, L. Pellegrini, E. De Santis, G. Sette, A. Eramo, P. Sale, E. Mari, A. Santoro, A. Raco, M. Salvati, R. De Maria, and M. A. Russo. 2011. "Pro-inflammatory gene expression in solid glioblastoma microenvironment and in hypoxic stem cells from human glioblastoma." $J$ Neuroinflammation 8:32. doi: 10.1186/1742-2094-8-32.

Taguchi, A., D. C. Blood, G. del Toro, A. Canet, D. C. Lee, W. Qu, N. Tanji, Y. Lu, E. Lalla, C. Fu, M. A. Hofmann, T. Kislinger, M. Ingram, A. Lu, H. Tanaka, O. Hori, S. Ogawa, D. M. Stern, and A. M. Schmidt. 2000. "Blockade of RAGE-amphoterin signalling suppresses tumour growth and metastases." Nature 405 (6784):354-60. doi: 10.1038/35012626.

Takino, T., M. Nakada, H. Miyamori, J. Yamashita, K. M. Yamada, and H. Sato. 2003. "CrkI adapter protein modulates cell migration and invasion in glioblastoma." Cancer Res 63 (9):2335-7.

Tazi, J., N. Bakkour, and S. Stamm. 2009. "Alternative splicing and disease." Biochim Biophys Acta 1792 (1):14-26. doi: 10.1016/j.bbadis.2008.09.017.

Voldborg, B. R., L. Damstrup, M. Spang-Thomsen, and H. S. Poulsen. 1997. "Epidermal growth factor receptor (EGFR) and EGFR mutations, function and possible role in clinical trials." Ann Oncol 8 (12):1197-206.

Wahl, M. C., C. L. Will, and R. Luhrmann. 2009. "The spliceosome: design principles of a dynamic RNP machine." Cell 136 (4):701-18. doi: 10.1016/j.cell.2009.02.009.

Wang, F., M. Kan, J. Xu, G. Yan, and W. L. McKeehan. 1995. "Ligand-specific structural domains in the fibroblast growth factor receptor." J Biol Chem 270 (17):10222-30.

Wang, F., M. Kan, G. Yan, J. Xu, and W. L. McKeehan. 1995. "Alternately spliced NH2- terminal immunoglobulin-like Loop I in the ectodomain of the fibroblast growth factor (FGF) receptor 1 lowers affinity for both heparin and FGF-1." J Biol Chem 270 (17):10231-5.

Wang, H., M. Zhou, B. Shi, Q. Zhang, H. Jiang, Y. Sun, J. Liu, K. Zhou, M. Yao, J. Gu, S. Yang, Y. Mao, and Z. Li. 2011. "Identification of an exon 4-deletion variant of epidermal growth factor receptor with increased metastasis-promoting capacity." Neoplasia 13 (5):461-71.

Wang, X. Q., and J. A. Rothnagel. 2001. "Post-transcriptional regulation of the gli1 oncogene by the expression of alternative 5' untranslated regions." J Biol Chem 276 (2):1311-6. doi: 10.1074/jbc.M005191200.

Wang, X., P. Sheng, X. Guo, J. Wang, L. Hou, G. Hu, C. Luo, Y. Dong, and Y. Lu. 2013. "Identification and expression of a novel MDM4 splice variant in human glioma." Brain Res 1537:260-6. doi: 10.1016/j.brainres.2013.07.054.

Wang, Z., H. Y. Jeon, F. Rigo, C. F. Bennett, and A. R. Krainer. 2012. "Manipulation of PK-M mutually exclusive alternative splicing by antisense oligonucleotides." Open Biol 2 (10):120133. doi: 10.1098/rsob.120133.

Warburg, O. 1956a. "On respiratory impairment in cancer cells." Science 124 (3215):269-70.

Warburg, O. 1956b. "On the origin of cancer cells." Science 123 (3191):309-14.

Weller, M., M. van den Bent, K. Hopkins, J. C. Tonn, R. Stupp, A. Falini, E. Cohen-Jonathan- Moyal, D. Frappaz, R. Henriksson, C. Balana, O. Chinot, Z. Ram, G. Reifenberger, R. Soffietti, W. Wick, and Glioma European Association for Neuro-Oncology Task Force on Malignant. 2014. "EANO guideline for the diagnosis and treatment of anaplastic gliomas and glioblastoma." Lancet Oncol 15 (9):e395-403. doi: 10.1016/S1470-2045(14)70011-7.

Werner, S., W. Weinberg, X. Liao, K. G. Peters, M. Blessing, S. H. Yuspa, R. L. Weiner, and L. T. Williams. 1993. "Targeted expression of a dominant-negative FGF receptor mutant in the epidermis of transgenic mice reveals a role of FGF in keratinocyte organization and differentiation." EMBO J 12 (7):2635-43.

Wong, A. J., J. M. Ruppert, S. H. Bigner, C. H. Grzeschik, P. A. Humphrey, D. S. Bigner, and B. Vogelstein. 1992. "Structural alterations of the epidermal growth factor receptor gene in human gliomas." Proc Natl Acad Sci U S A 89 (7):2965-9.

Xiang, C., R. Sarid, S. Cazacu, S. Finniss, H. K. Lee, A. Ziv-Av, T. Mikkelsen, and C. Brodie. 2007. "Cloning and characterization of human RTVP-1b, a novel splice variant of RTVP-1 in glioma cells." Biochem Biophys Res Commun 362 (3):612-8. doi: 10.1016/j.bbrc.2007.08.138.

Yadav, A. K., V. Vashishta, N. Joshi, and P. Taneja. 2014. "AR-A 014418 Used against GSK3beta Downregulates Expression of hnRNPA1 and SF2/ASF Splicing Factors." J Oncol 2014:695325. doi: 10.1155/2014/695325.

Yamada, S. M., F. Yamaguchi, R. Brown, M. S. Berger, and R. S. Morrison. 1999. "Suppression of glioblastoma cell growth following antisense oligonucleotidemediated inhibition of fibroblast growth factor receptor expression." Glia 28 (1):66-76.

Yamada, Y., T. Kuroiwa, T. Nakagawa, Y. Kajimoto, T. Dohi, H. Azuma, M. Tsuji, K. Kami, and S. Miyatake. 2003. "Transcriptional expression of survivin and its splice variants in brain tumors in humans." J Neurosurg 99 (4):738-45. doi: 10.3171/jns.2003.99.4.0738.

Yamaguchi, F., H. Saya, J. M. Bruner, and R. S. Morrison. 1994. "Differential expression of two fibroblast growth factor-receptor genes is associated with malignant progression in human astrocytomas." Proc Natl Acad Sci U S A 91 (2):484-8.

Yamaguchi, T., T. Okada, K. Takeuchi, T. Tonda, M. Ohtaki, S. Shinoda, T. Masuzawa, K. Ozawa, and T. Inaba. 2003. "Enhancement of thymidine kinase-mediated killing of malignant glioma by BimS, a BH3-only cell death activator." Gene Ther 10 (5):375-85. doi: 10.1038/sj.gt.3301897.

Yu, F., and W. M. Fu. 2014. "Identification of differential splicing genes in gliomas using exon expression profiling." Mol Med Rep. doi: 10.3892/mmr.2014.2775.

Yu, Y., X. Jiang, B. S. Schoch, R. S. Carroll, P. M. Black, and M. D. Johnson. 2007. "Aberrant splicing of cyclin-dependent kinase-associated protein phosphatase KAP increases proliferation and migration in glioblastoma." Cancer Res 67 (1):130-8. doi: 10.1158/0008-5472.CAN-06-2478.

Zalutsky, M. R., R. P. Moseley, H. B. Coakham, R. E. Coleman, and D. D. Bigner. 1989. "Pharmacokinetics and tumor localization of 131I-labeled anti-tenascin monoclonal antibody 81C6 in patients with gliomas and other intracranial malignancies." Cancer Res 49 (10):2807-13.

Zhang, J., and J. L. Manley. 2013. "Misregulation of pre-mRNA alternative splicing in cancer." Cancer Discov 3 (11):1228-37. doi: 10.1158/2159-8290.CD-13-0253.

Zhang, Z., F. Lotti, K. Dittmar, I. Younis, L. Wan, M. Kasim, and G. Dreyfuss. 2008. "SMN deficiency causes tissue-specific perturbations in the repertoire of snRNAs and widespread defects in splicing." Cell 133 (4):585-600. doi: 10.1016/j.cell.2008.03.031.

Zheng, P. P., A. M. Sieuwerts, T. M. Luider, M. van der Weiden, P. A. Sillevis-Smitt, and J. M. Kros. 2004. "Differential expression of splicing variants of the human caldesmon gene (CALD1) in glioma neovascularization versus normal brain microvasculature." Am J Pathol 164 (6):2217-28. doi: 10.1016/S00029440(10)63778-9.

Zheng, P. P., M. van der Weiden, and J. M. Kros. 2005. "Differential expression of Hela-type caldesmon in tumour neovascularization: a new marker of angiogenic endothelial cells." J Pathol 205 (3):408-14. doi: 10.1002/path.1700.

Zhu, H., R. L. Carpenter, W. Han, and H. W. Lo. 2014. "The GLI1 splice variant TGLI1 promotes glioblastoma angiogenesis and growth." Cancer Lett 343 (1):51-61. doi: 10.1016/j.canlet.2013.09.014. 